Journal of Educational

and Psychological Sciences

Volume (5), Issue (44): 30 Nov 2021

P: 89 - 105
AJSRP

ISSN: 2522-3399
مجلة العلوم

التربوية والنفسية

المجلد (5)، العدد (44): 30 نوفمبر 2021 م

ص: 89 - 105

\title{
The effectiveness of the e-learning system, the future gateway to develop the academic achievement in chemistry course for female students in the second secondary stage in Jeddah
}

\section{Safieh Muhammad Ali Omeish}

Ministry of Education || KSA

\begin{abstract}
This current research aimed at investigate the effectiveness of the e-learning system (the future portal) in developing the academic achievement of chemistry for second-grade secondary school students in Jeddah, and the research followed the experimental approach. The tool consisted in following an e-learning system using the electronic future gate system that was applied to an experimental group of (50) female students, against a control group of (50) students who studied using the traditional method. The study sample was randomly selected The results of the post-test showed that there are statistically significant differences at the level of significance $(\alpha \leq 0.05)$ between the experimental group and got a total mean (40.38 out of 50) and the control group and got a total mean (36.82 out of 50), and the difference is in favor of the experimental. This indicates that the method of teaching using e-learning (the gate of the future) has improved and promoted academic achievement in chemistry for second-grade secondary students in Jeddah., and the research came out with a set of recommendations, the most important of which is the need to adopt the use of the electronic learning system (the future gate) in teaching chemistry to students, due to its effectiveness and benefit in developing their academic achievement.
\end{abstract}

Keywords: E-learning, Future Gate, Academic Achievement, chemistry, Jeddah City, Saudi.

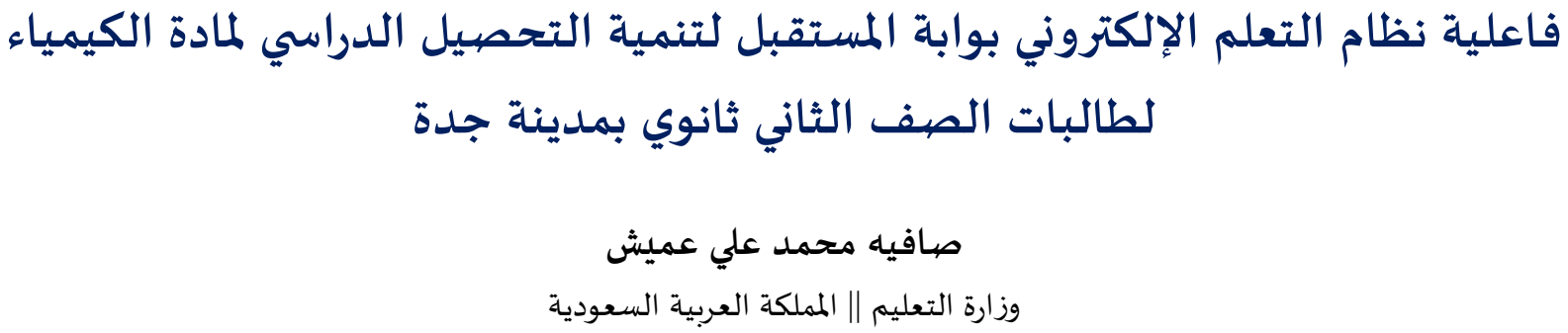

المستخلص: هدف البحث الحالي إلى الكشف عن فاعلية نظام التعلم الإلكتروني (بوابة المستقبل) في تنمية التحصيل الدراسي بمادة الكيمياء لطالبات الصف الثاني ثانوي بمدينة جدة، واتبع البحث المنهج التجريبي، وتمثلت الأداة في اتباع نظام تعلم إلكتروني باستخدام

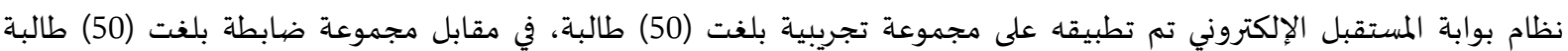
درسن باستخدام الطريقة التقليدية. وقد تم اختيار عينة الدراسة بالطريقة العشوائية، وقد أظهرت نتائج الاختبار البعدي أن هنالك مأك

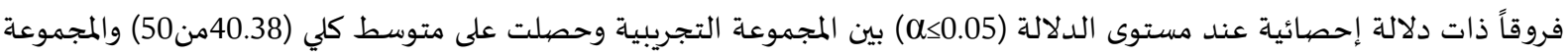
الضابطة وحصلت على متوسط كلي (36.82من50)، والفرق لصالح التجريبية؛ وهذا يدل على أن طريقة التدريس باستخدام التعليم الإلكتروني (بوابة المستقبل) قد حسّنت ونمّت التحصيل الدراسي في مادة الكيمياء لطالبات الصف الثاني ثانوي بمدينة جدة، وقدئ وقد خرج البحث بمجموعة من التوصيات أهمها الحاجة إلى تبني استخدام نظام التعلم الإلكتروني (بوابة المستقبل) في تدريس مادة الكيمياء لطالبات الصف الثاني ثانوي وذلك لفعاليته وفائدتا في تنمية التحصيل الدراسي لديهن. 
إنّ ما يواجه العالم المعاصر من تحديات ناتجة عن ثورة المعلومات والاتصالات، قادتهُ إلى إجراء مُراجعة

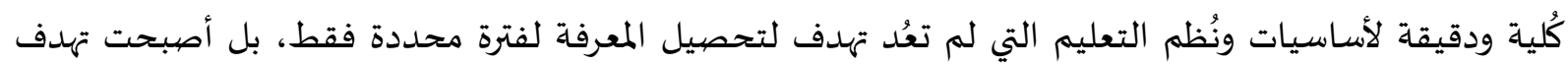
وتركز على ضرورة توظيف المعرفة المُستفادة من التعليم في تشكيل البنية المعرفية والتفكيرية للطالب (حمود، 2008).

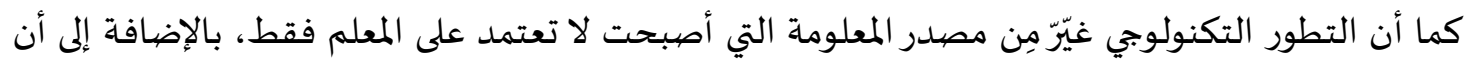

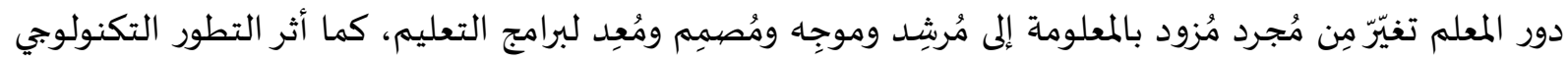

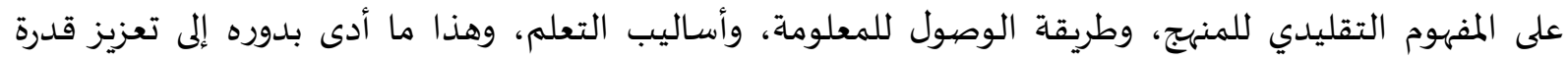

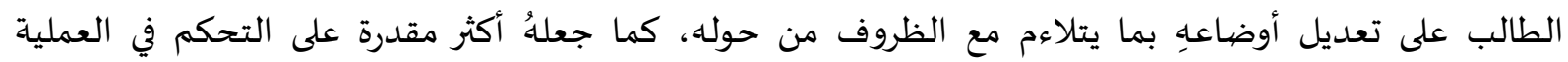

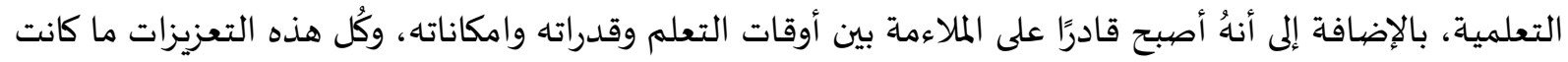

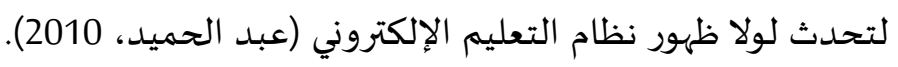

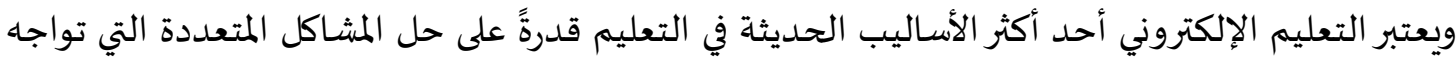

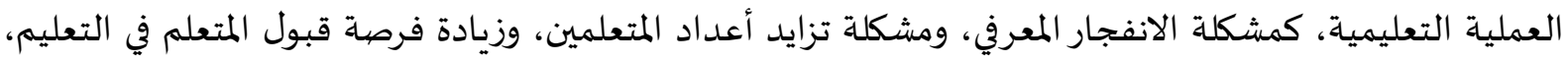
بالإضافة إلى أن التعليم الإلكتروني قادر على تعزيز إمكانية تدريب العاملين في العملية التعليمية دون الحماجة العادية لتركهم

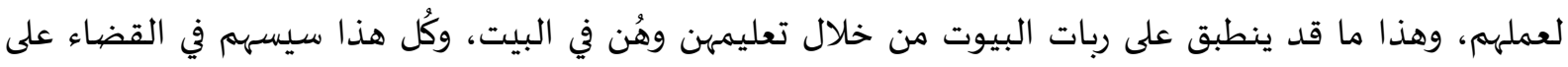

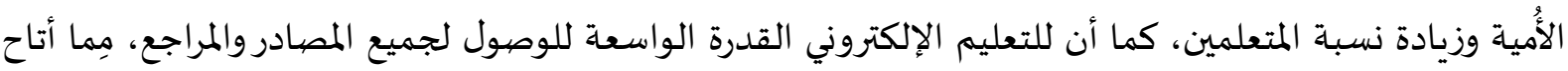

مجموعة متنوعة من الفرص التعليمية للأفراد (Tegene, 2014).

كما أن التعليم الإلكتروني يهدف بشكل رئيسي إلى دعم العملية التعليمية من خلال تزويدها بأفضل الأساليب التعليمية التفاعلية، وذلك من أجل مساعدة العملية التعليمية على مواجهة كافة التحديات التي تقف

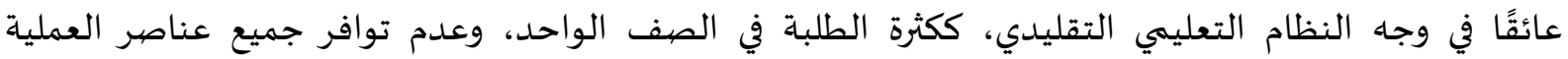
التعليمياة، ضُعف الإمكانات واقتصارها على الامور الأساسية فقط، عدم استخدام أساليب ذات كفاءة وفاعلية في تحسين القدرة الابداعية ومراعاة الفروق الفردية لدى الطلبة (الأخرس، 2018).

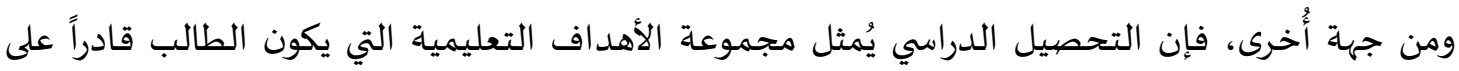

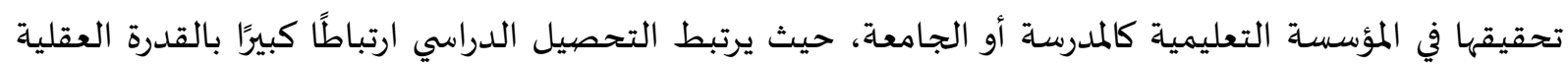

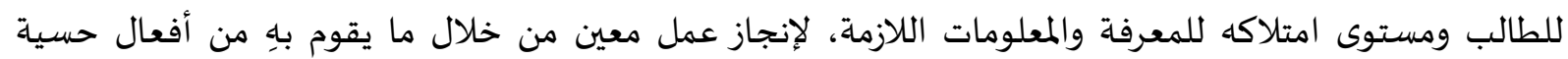
وذهنية وفطرية، وتختلف هذه القدرة من طالب إلى آخر (عسيري، 2016).

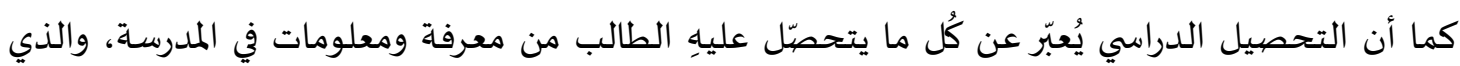

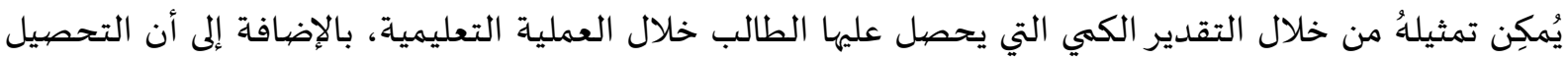

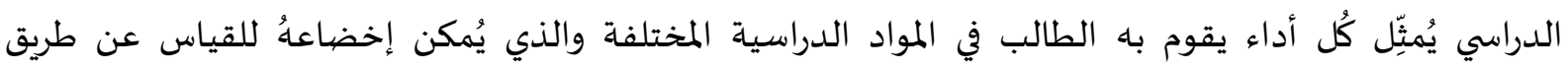

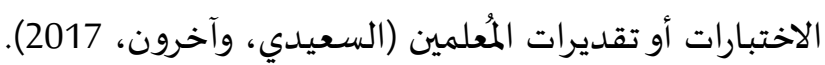

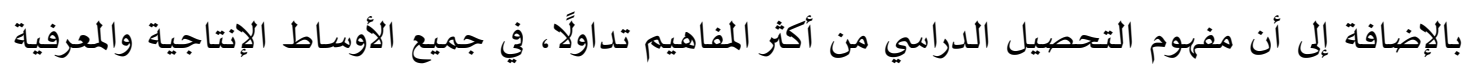

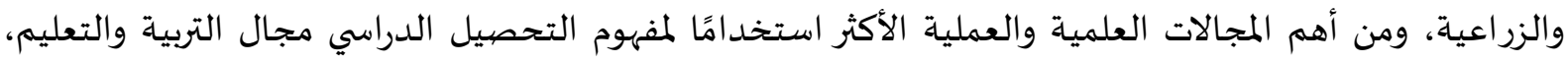

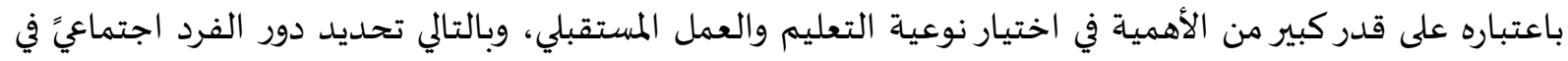


مجتمعِِ، ومكانتهِ الاجتماعية التي يستطيع تحقيقها، وكيف ينظر لذاته، وطبيعة شعور النجاح لدياه ومستوى لئه الطموح لديه.

ومن خلال ما تم طرحاُ سابقًا عن فوائد التعليم الإلكتروني ودورهُ المؤثر في العملية التعليمية، بالإضافة إلى لئ

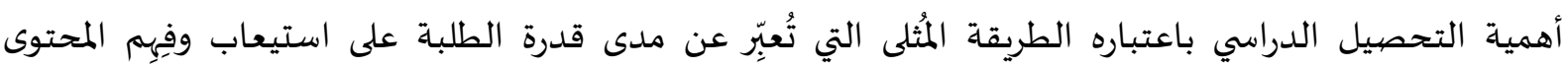

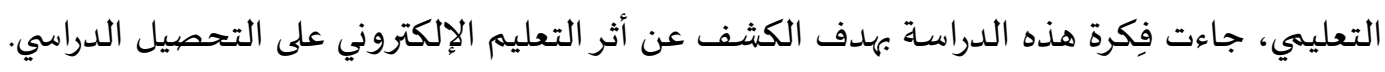

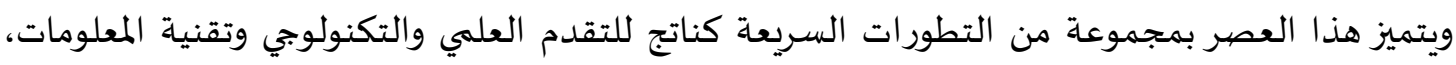

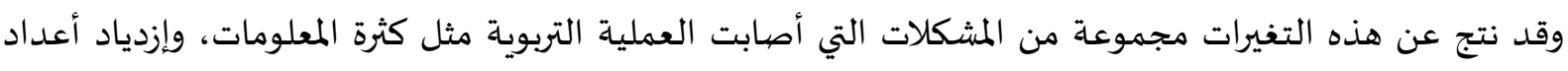

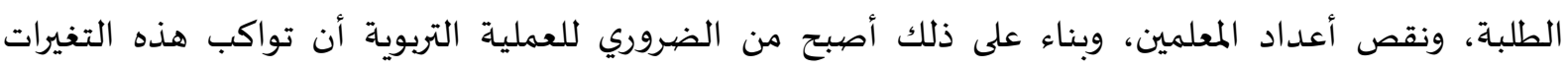
والتطورات.

وقد أكدت الدراسات التربوية الحديثة على ضرورة التحول من وسائل التعلم التي تعتمد على الحفظ

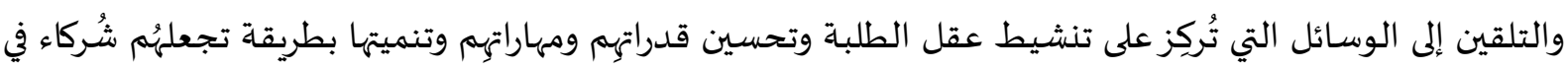

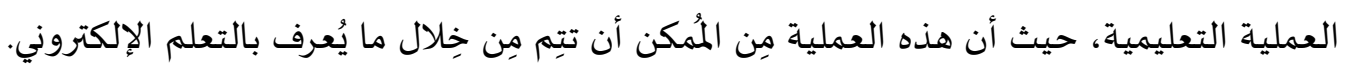

مشكلة الدراسـة وتساؤلاتها: يعاني الطلبة بشكل عامّ، وطلبة الصف الثاني ثانوي بشكل خاصّ، من صعوبات فئات في عملية الاستيعاب

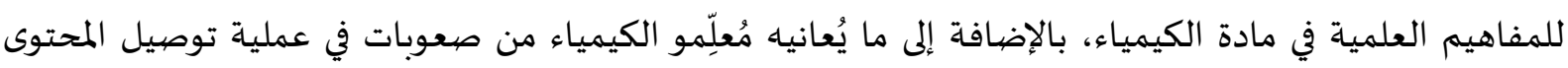

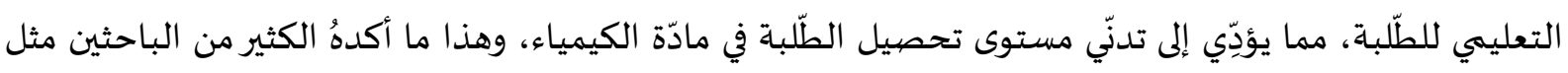
(الحيجي، 2018؛ العزاوي، 2017). وعلى الرغم من أهمية مادة الكيمياء إلا أنهُ لا يزال هناك شعور، الكور بالكره والخوف والقلق اتجاه هذه المادة،

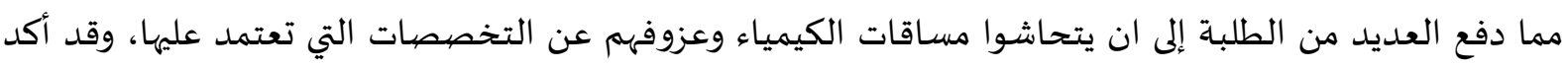

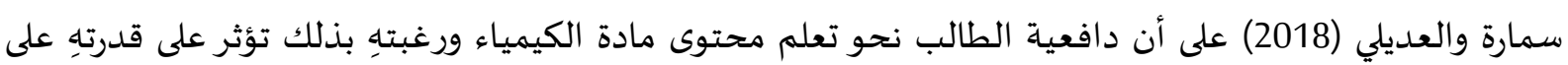
تعلم تلك المادة. كما أشارت العديد من الدراسات مثل دراسة (قشمر، 2019؛ أبو زاهره، 2020) إلى أن استراتيجيات

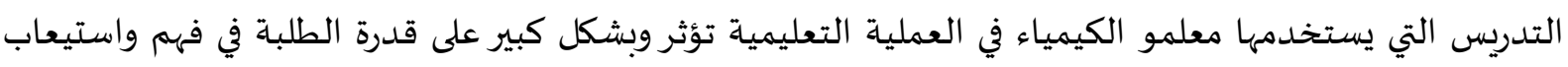

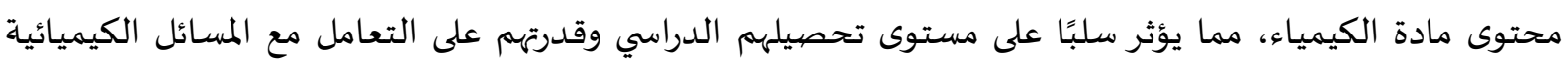

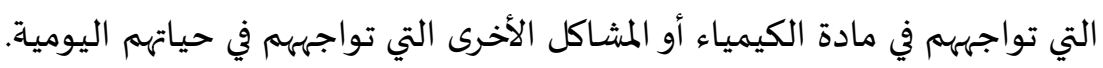

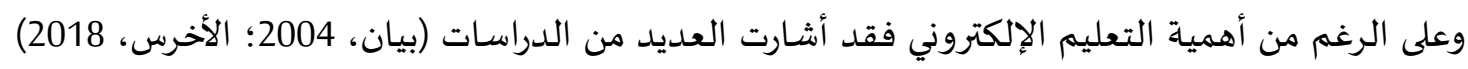

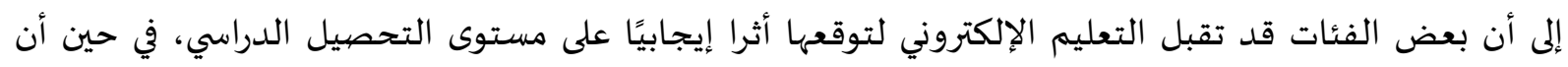

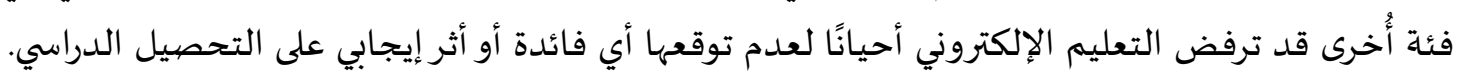

أسئلة الدراسـة: - n كُل ما سبق يشكّل دافعًا لدراسة هذه المشكلة وضرورة الإحاطة بجوانهها وأبعادها كافة، والتي يمكن بلورتها بالسؤال التالي: ما فاعلية نظام التعليم الإلكتروني (بوابة المستقبل) في تنمية التحصيل الدراسي لمادة الكيمياء لطالبات

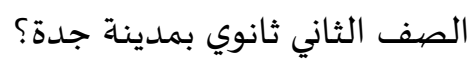
وقد انبثقت عن هذا السؤال التساؤلات التالية: 


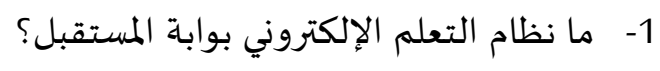

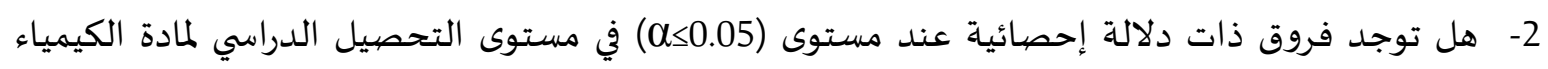

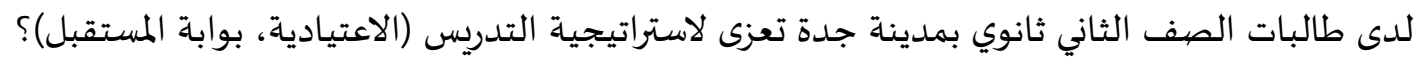

أهداف الدراسة

تسعى الدراسـة الحالية إلى:

1- التعريف بنظام التعلم الإلكتروني بوابة المستقبل.

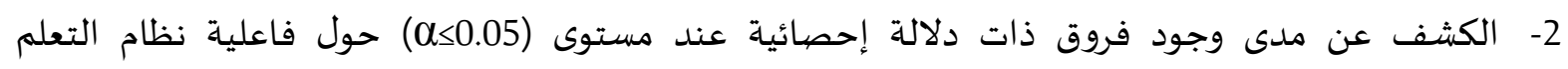
الإلكتروني (بوابة المستقبل) في تنمية التحصيل الدراسي بمادة الكيمياء لطالبات الصف الصفات الثاني ثانوي بمدينة

تنبثق أهمية الدراسة من خلال: الداسل

الأهمية النظرية:

تكمن أهميتها من خلال أهمية المادة التعليمية وأهمية الفئة العمرية التي تناولتها الدراسة. - أهمية موضيوع تنمية التحصيل الدراسي بشكل عام وفي مادة الكيمياء بشكل خاص الذي الذية أخذ مكان هام في الأبحاث التربوية.

رفد المكتبة التربوية بالمزيد من الدراسات والأبحاث المُتعلقة بنموذج برونر وأثره في حل المشكلات التفكير الرياضي.

قد يسهم الكشف عن فاعلية نظام التعلم الإلكتروني (بوابة المستقبل) في تنمية التحصيل الدراسي لمادة الكيمياء لطالبات الصف الثاني ثانوي، في تعزيز المعرفة النظرّيّة لمفهومي التعلم الإلكتروني والتحصيل

الدراسي.

الأهمية التطبيقية:

- - مأهمية نظام التعليم الإلكتروني بوابة المستقبل الذيه قد يكون أنموذجًا للمعلمين.

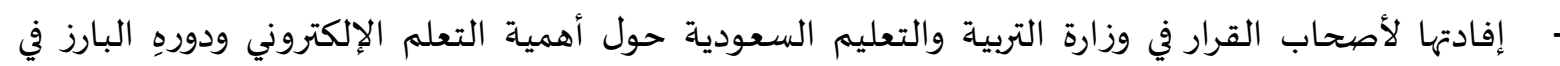
تحسين مستوى العملية التعليمية. - ق قد تفيد القائمين على إعداد المعلمين وفي وزارة التربية والتعليم عن طريق تدريبهم على أساليب التعليم الإلكتروني وكيفية تطبيقهِ بالغرفة الصفية.

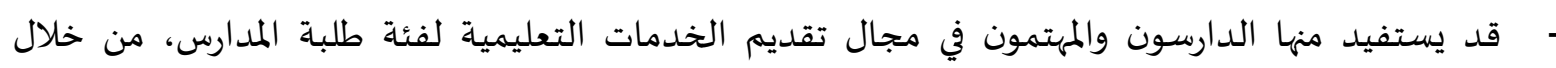
التعرف على استراتيجيات التدريس الملائمة لهم.

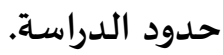

تقتصر هذه الدراسة على الحدود الآتية:

الحدود الموضيوعية: التعلم الإلكتروني وفاعليتهِ في تنمية التحصيل الدراسية الدئي في مادة الكيمياء. الحدود البشرية: عينة من طالبات الصف الثاني ثانوي. 
- التعلم الإلكتروني: "هو أحدث أنواع التعليم المستخدمة في المؤسسات التربوية والتي تعتمد بشكل أساسي على

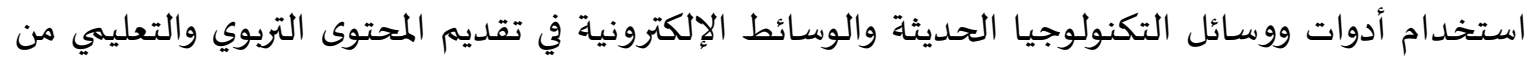

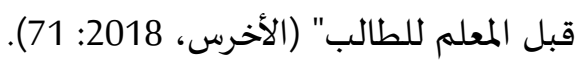

كما يُعبر مصطلح التعليم الإلكتروني عن "العملية التعليمية التي تتم بواسطة أدوات التكنولوجيا والإنترنت، كما

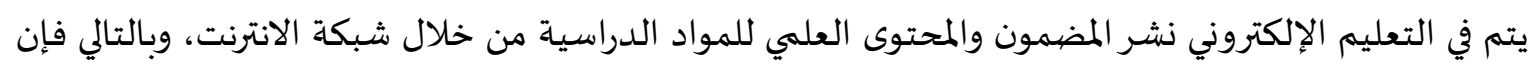

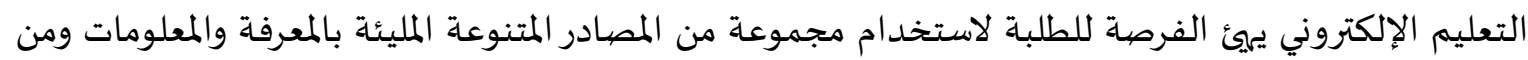
خارج المادة التعليمية والحصية الصفية" (عثمان، 2009).

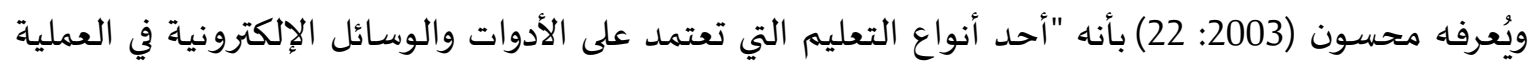

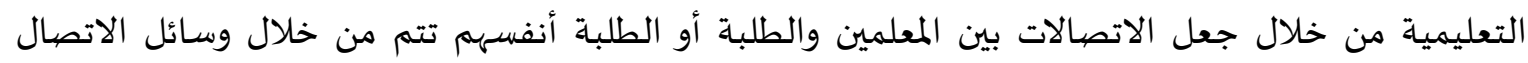
الإلكترونية". بوابة المستقبل: برنامج أطلقته وزارة التعليم للتحوّل نحو التعليم الرقهي، ولقد اتخذت من الطالب والمعلم

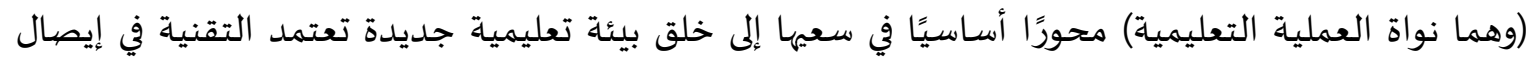

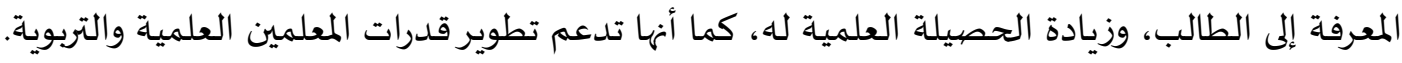

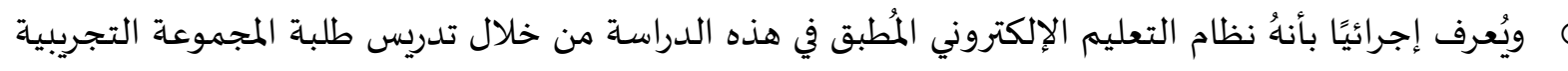

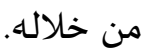
التحصيل الدراسي: هو "مُحصيّلة ما يتعلمهُ الطالب من خلال تعلمه للمحتوى التعليمي، ويُعبّر عن المدى الذي الذي

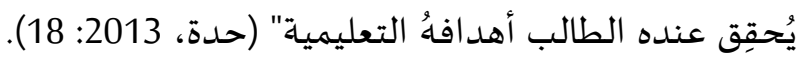

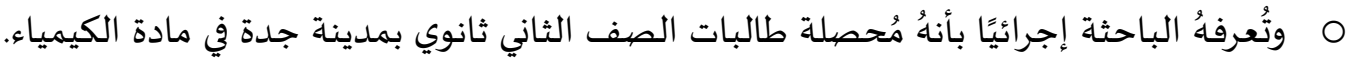

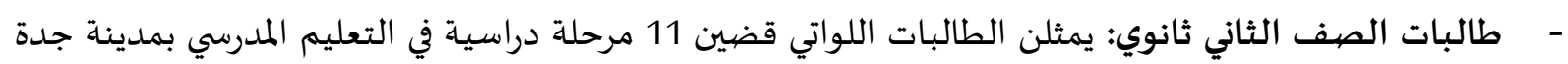
السعودية، وتتراوح أعمارهن (17-18) عام.

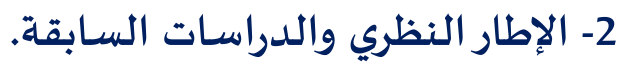

$$
\text { أولًا - الإطار النظري. }
$$

يعتبر التعليم الإلكتروني منظومة شاملة تعتمد على استخدام تكنولوجيا المعلومات والاتصالات بشكل فعّال

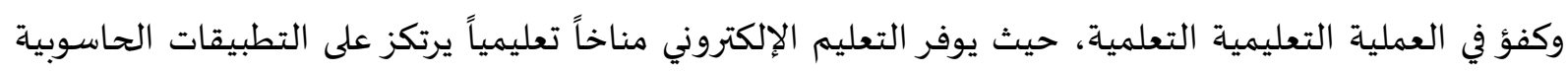
والانترنت، التي تساعد المتعلم على التعلم والوصول إلى مصادره بأي وقت وأي مكانه التعان. ويعد ظهور التعليم الإلكتروني استجابة حقيقية من قبل المؤسسات التربوية لموجة التقدم التكنولوبي التي

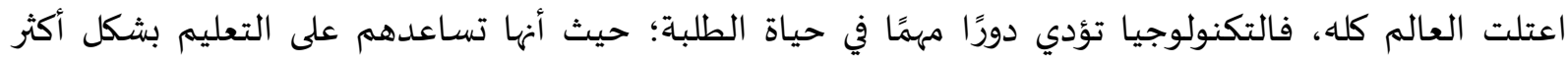


فاعلية وتستثير لديهم حب الاكتشاف والتجريب، لذا نجد معظم الطلبة يهتمون اهتمامًا بالتكنولوجيا وبكافة

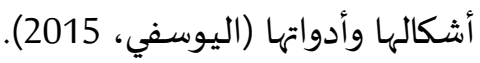
واليوم أصبح التعليم الإلكتروني يعتمد على وسائل تكنولوجيا المعلومات الحديثة كالكمبيوتر واللوحات

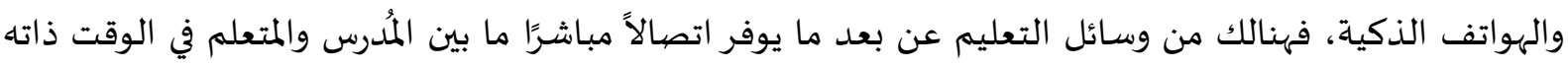

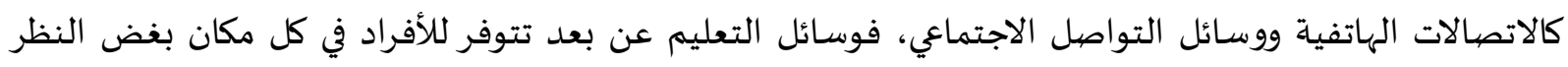

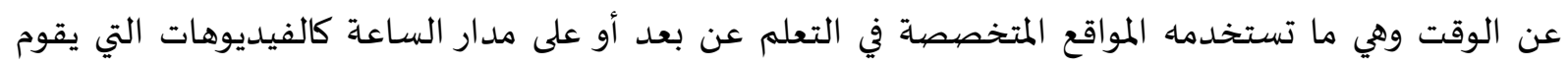

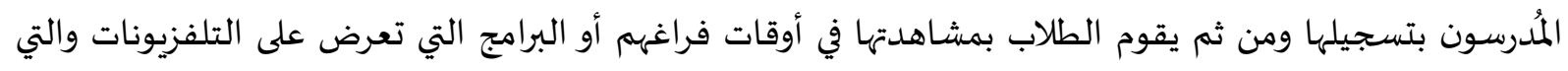

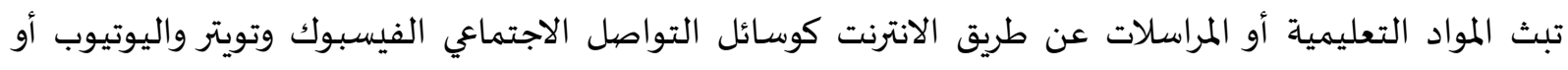
البريد الإلكتروني (عميرة وآخرون، 2019).

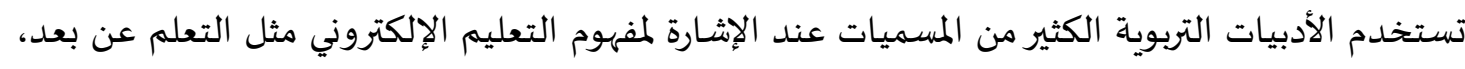

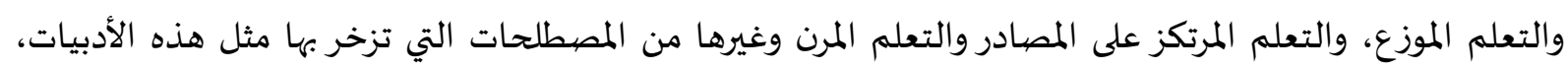

فالمعاني والتعريفات تتباين بالنسبة للمفهوم بحسب النظرة لله والفهم لجوانبه (Boettcher \& Conrad, 2010).

$$
\text { أهداف التعليم الإلكتروني. }
$$

يسعى التعليم الإلكتروني كما ذكر الهرش وآخرون (2010) لتحقيق الأهداف التالية:

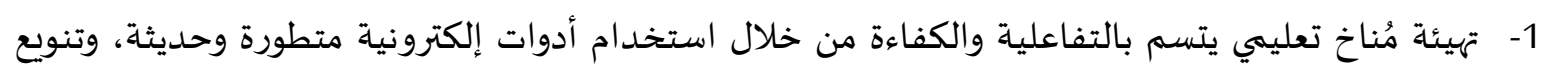

$$
\text { مصيادر التعلم. }
$$

2- تحسين العلاقة بين المؤسسة التربوية والمجتمع المحلي من حولها بيئيًا واجتماعيًا.

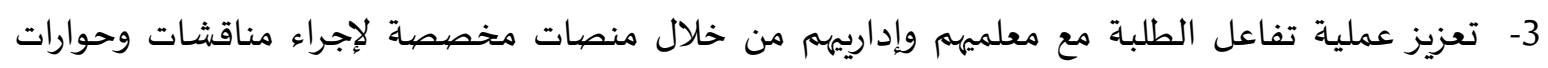

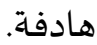

4- تدريب المعلمين وإكسابهم للمهارات اللازمة للتعامل مع التقنيات التكنولوجية الحديثة.

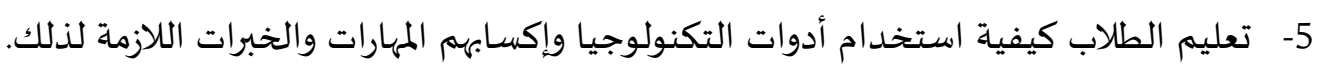

6- تدريب المعلمين بطريقة تتلاءم مع التطورات التكنولوجية الحديثة والمتطورة باستمرار.

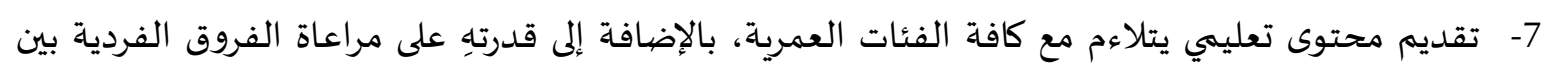
الطلبة.

وقد أشارت باروم (2005) إلى أن للتعليم الإلكتروني أهداف خاصة فيه يتميز بها عن مختلف وسائل

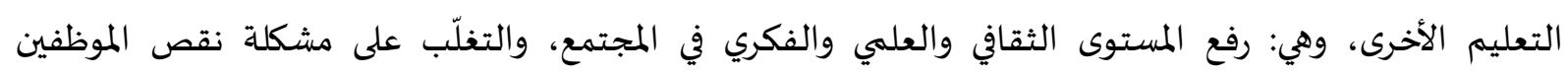

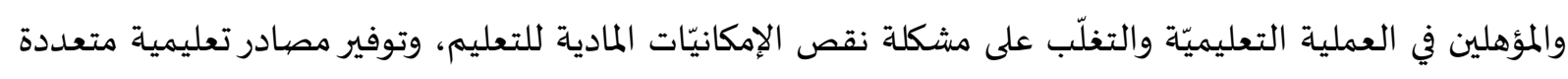

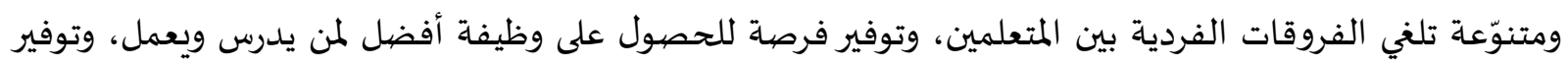
فرصة تعليميّة لمن لا تسمح له ظروف الحياة بالانتظام بالتعليم التقليدي.

أهمية التعليم الإلكتروني.

$$
\begin{aligned}
& \text { للتعليم الإلكتروني فوائد عديدة من أهمها (عميرة وآخرون، 2019): }
\end{aligned}
$$

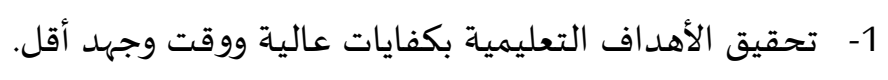

$$
\begin{aligned}
& \text { 2- - تحقيق التعلم بطرق تناسب خصائص المتعلم وبأسلوب مشوق وممتع. } \\
& \text { 3- توفير مصادر ثرية للمعلومات يمكن الوصول إلها في وقت قصير. }
\end{aligned}
$$


4- يحفز المتعلم في مهارات التعلم الذاتي والاعتماد على نفسـه في اكتساب الخبرات والمعارف وإكسابه أدوات

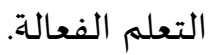

5- يكسب التعليم الإلكتروني الدافعية للمعلم والمتعلم في مواكبة العصر والتقدم المستمر في التكنولوجيا والعلوم والتواصل مع المستجدات في شتى المجالات.

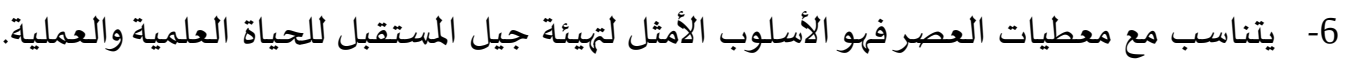

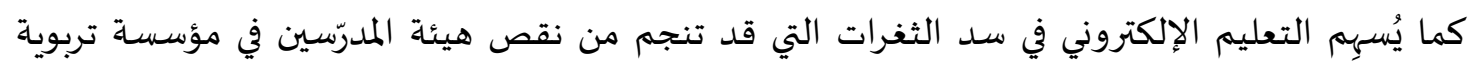

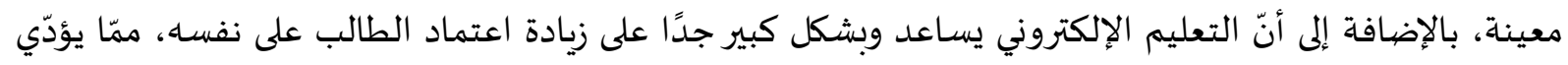

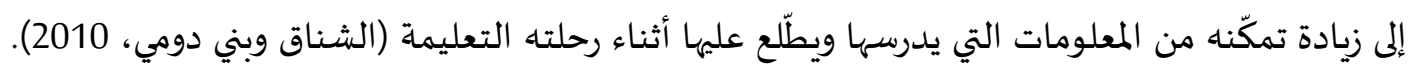

التحصيل الدراسي: تصني: تعتبر العملية التعليمية التعلُمية أحد أهم مؤشرات تقدُّم البشرية وتطور الدول، حيث إن مستوى تطور أي

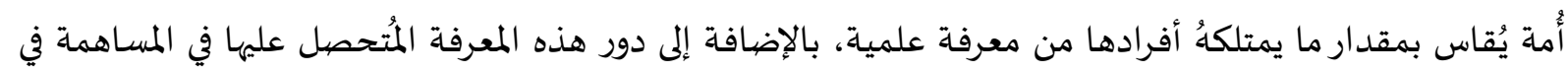

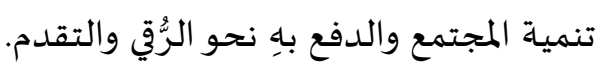
ويقيس التحصيل الدراسي حجم المعرفة العلمية والمفاهيم العلمية التي يمتلكها الطالب، لذلك يعتبر أحد

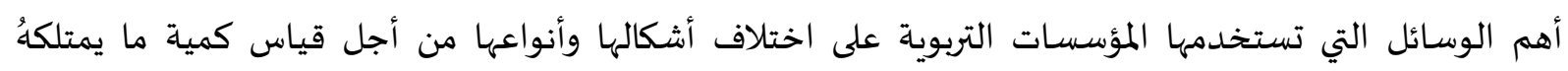

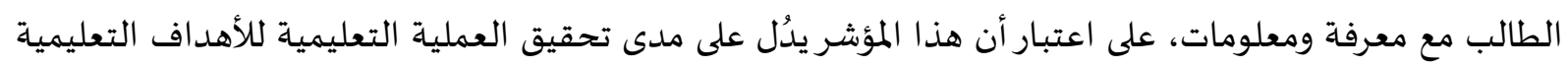

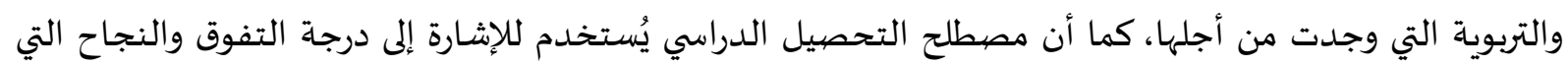

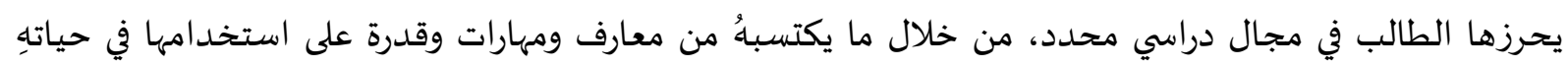
اليومية (علام، 2006).

وبهدف قياس مستوى تحصيل الطلبة تلجأ المؤسسات التربوية لإجراء مجموعة من الاختبارات اليومية أو

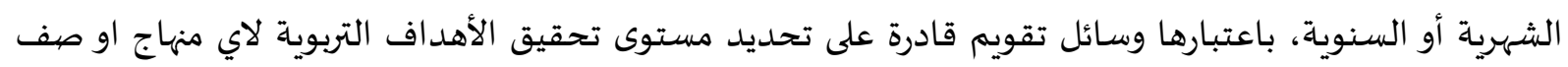

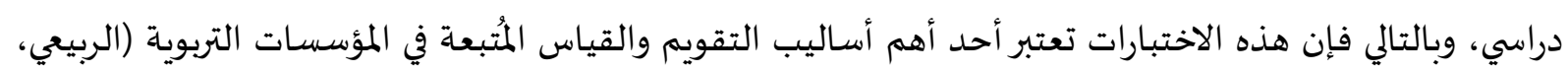
2006

ويشير (مصطفى، 2001) إلى أن السبب الرئيسي في ضُعف تحصيل الطلبة دراسيًا أو ما يُعرف بالتأخُّر

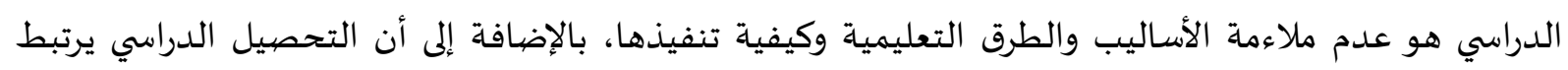

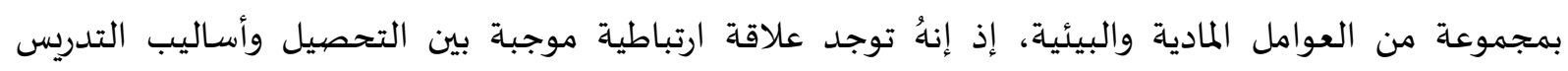

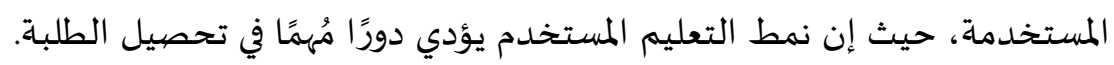

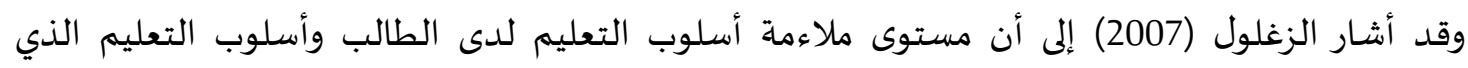

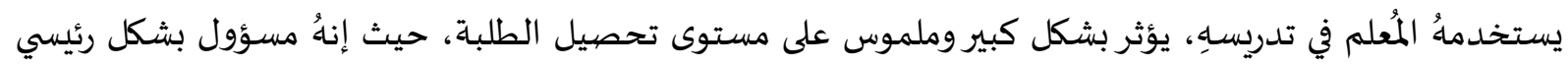

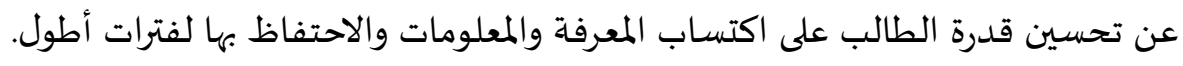

واقع التعليم الإلكتروني في السعودية: تبنت الحكومة السعودية مجموعة من الاستراتيجيات والإجراءات المتنوعة على المستوى الوطني بهدف فيدف دعم

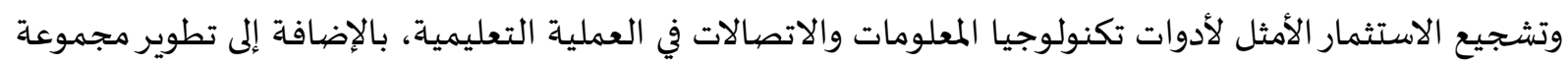

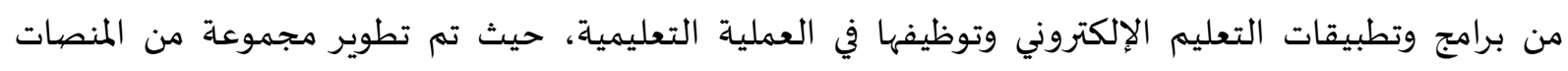
التعليمية، كمنصبة بوابة عين على اليوتيوب، ومنصاة بوابة المستقبل للتعليم المدرسي، كذلك تم انشاء (20) قناة 
تبُث الدروس العلمية بشكل ممنهج، وبالنسبة للتعليم العالي فقد أطلقت الجامعات السعودية الحكومية والخاصة

منصة التعلم الإلكتروني، مثل نظام بلاك بورد لدعم التعلم الإلكتروني لطلبة الجامعات (Algahtani et al., 2020).

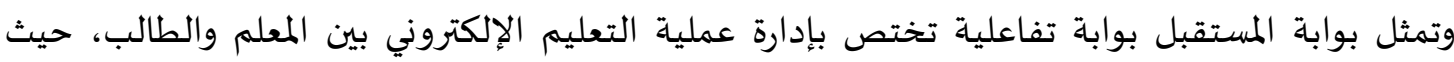

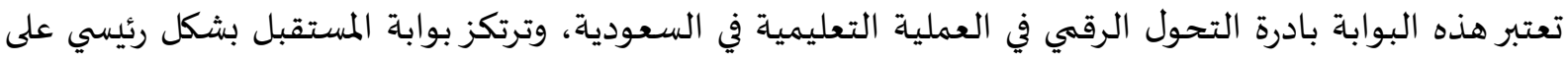

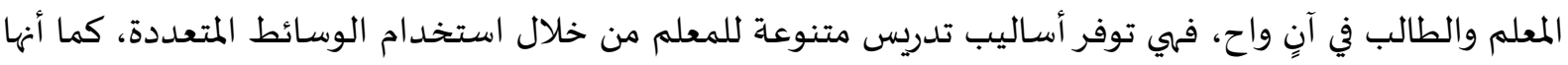
توفر للطالب فرصة التعلم بأي وقت ومن أي مكان، بالإضافة إلى أن بوابة المستقبل تشمل جميع توفيع عناصر العملية

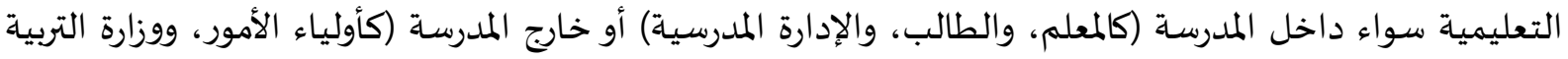
والتعليم) (الجار الله والخريجي، 2020).

وتهدف بوابة المستقبل بشكل رئيس إلى (Algahtani et al., 2020):

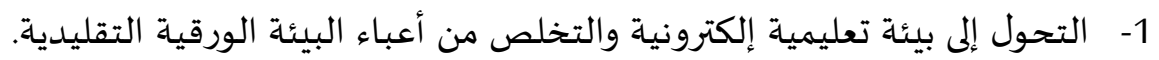

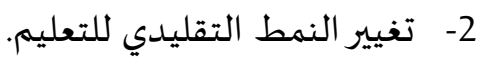
3- توسيع عمليات التعليم والتعلم إلى خارج نطاق الفصليم الدراسي والبيئة المدرسية. 4- إيجاد بيئة تعليمية ممتعة بالتفاعل الإيجابي بين الطلاب والمعلمين.

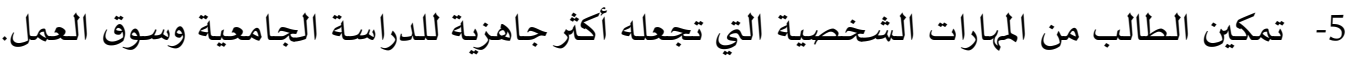
6- الاستفادة من إقبال الطلاب على التقنيات الحديثة وتوجيههم للاستخدام الإيجابي لمنتجات التهنية التهنية.

ثانياً- الدراسات السابقة:

تناولت الدراسة الحالية الدراسات التي تنسجم خصائصها مع مجتمع الدراسة الحالي قدر الإمكان والمتمثل

في (طلبة المدارس) بالرغم من وجود دراسات تناولت متغيرات الدراسة على عينات أخرى مثل طلبة الجامعات.

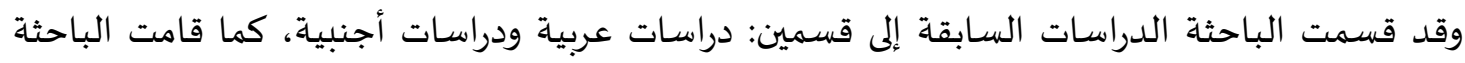

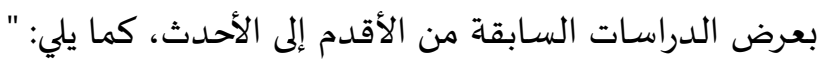

- أجرى حسين (2012) دراسة هدفت إلى معرفة أثر التعليم الإلكتروني عبر منظومة الموجة التعليمية على الماتل

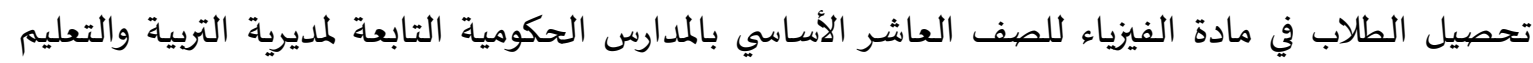

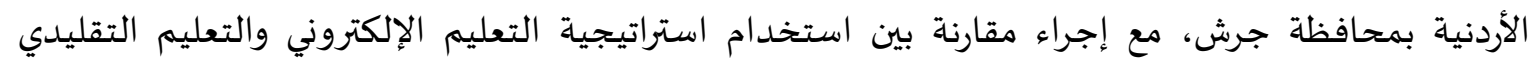

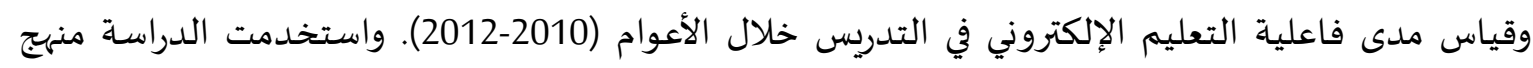

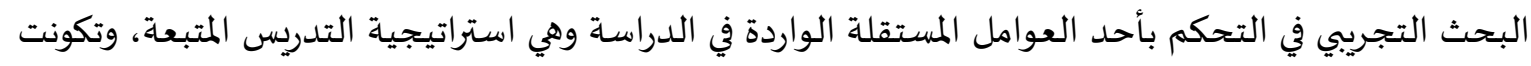

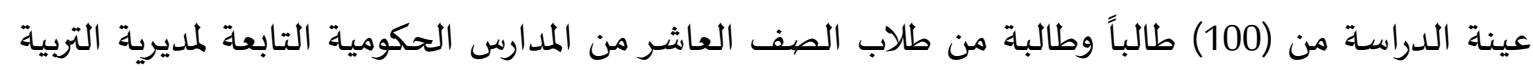

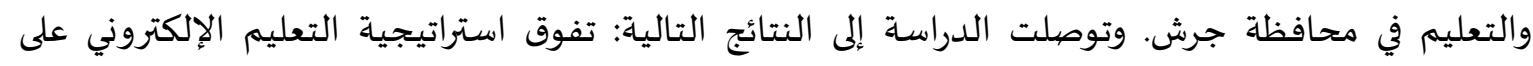
الطريقة التقليدية في مستوى تحصيل طلاب الصف العاشر الأساسي في مادة الفيزياء. تفوق الاناث في التحصيل العلمي على الذكور عند التدريس بطريقة التعليم الإلكتروني. وقام أبو سوار (2013) بدراسة هدفت إلى التعرف على فعالية استخدام الكتاب الإلكتروني في التحصيل

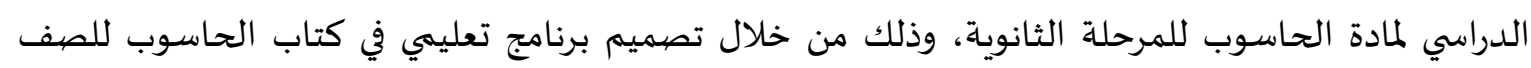

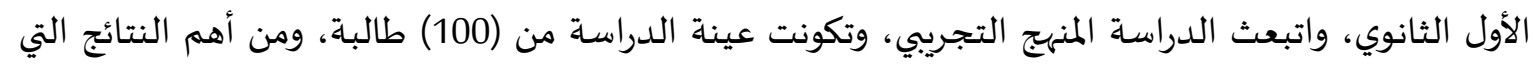

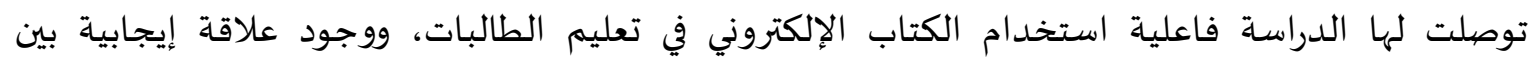


استخدام الكتاب الإلكتروني ورفع مستوى التحصيل لدى الطالبات، كما أثبتت الدراسة تميز الطالبات اللاتي درسن بالكتاب الإلكتروني مقارنة باللاتي درسن بالطريقة التقابت التعليدية. أجرى زاري، ساريخاني، سلاري ومنصيوري (Zare, Sarikhani, Salari \& Mansouri, 2016) دراسة هدفت إلى بإئل التعرف على تأثير التعليم الإلكتروني على الإبداع ومعرفة المحتوى لدى طلاب الكيمياء بجامعادة (Payame Noor)

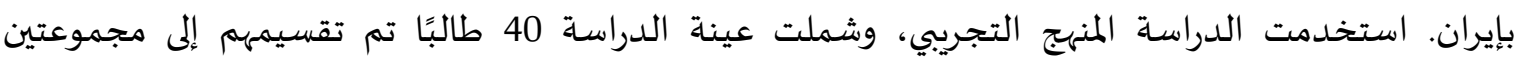

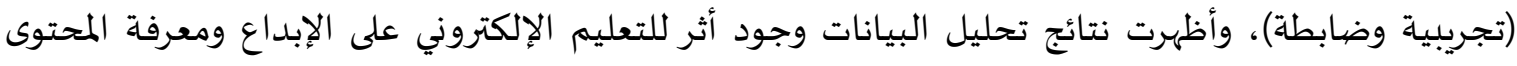

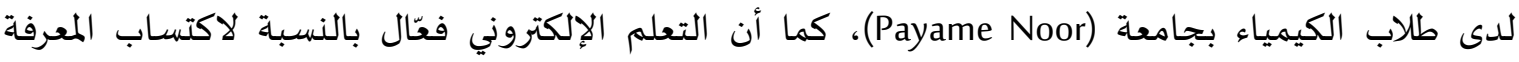
والإبداع بين طلاب الكيمياء. وقدم السعيدي وآخرون (2017) دراسة هدفت إلى التعرف على أثر التعليم الإلكتروني في تدريس الرياضيات

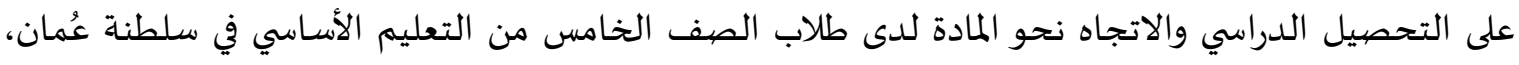

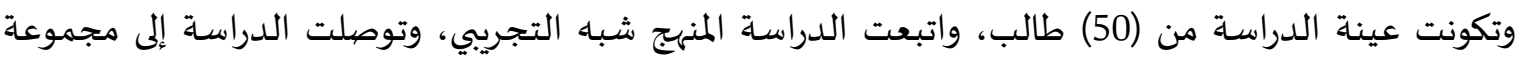

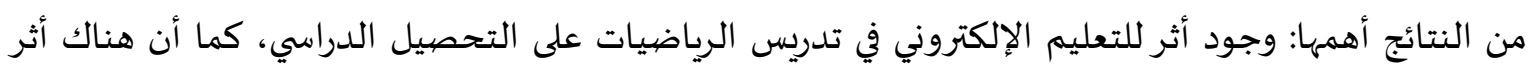
للتعليم الإلكتروني على اتجاه الطلبة نحو مادة الرياضيات.

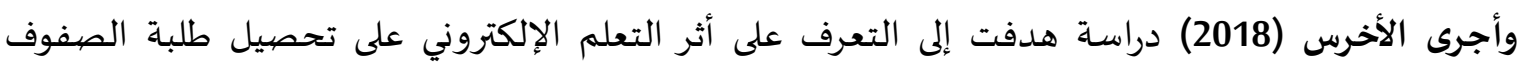

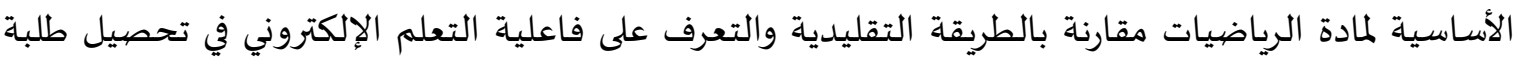
الصفوف الأسساسية في محافظة العاصمة لمادة الرياضيات وفق متغيري التخصص والجيه الجنس. وتكونت عينة

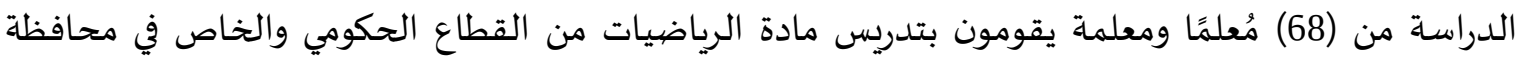

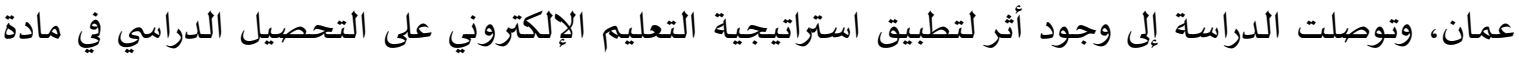

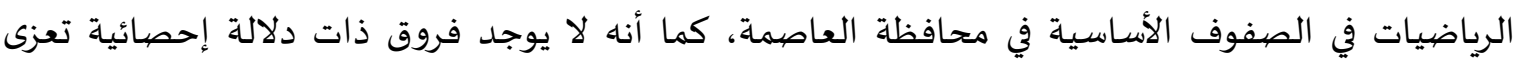

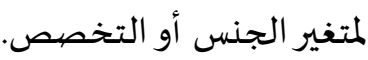

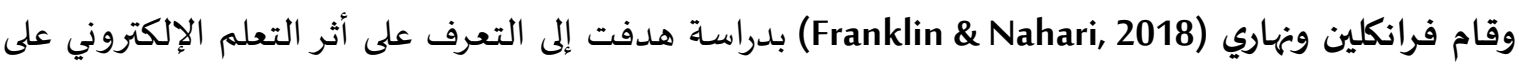

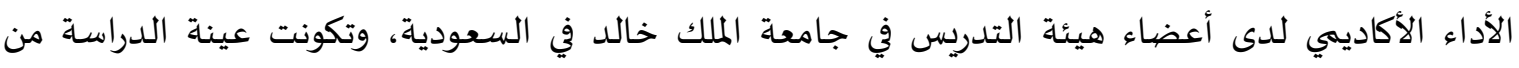
(163) عضو هيئة تديس، وتم استخدام نمذجة المعادلة الهيكلية (SEM) لتقييم تأثير المتغيرات الخارجية على وتكوني

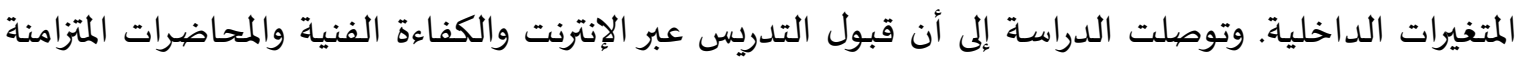

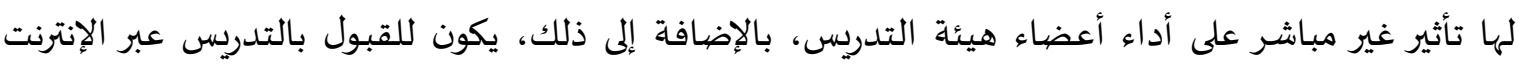

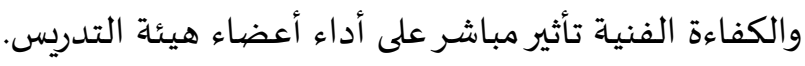

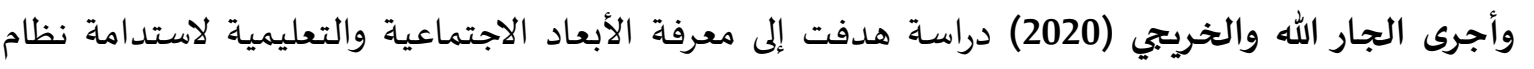
التعلم الإلكتروني في المملكة العربية السعودية، وقد اتبعت الدراس الدراسة أسلوب تحليل المحتوى من خلال تحليل مجموعة من التغريدات في منصة تويتر، وقد تم تحليل (13975) تغريدة لمستفيدين من التعلم الإلكتروني في في فئل

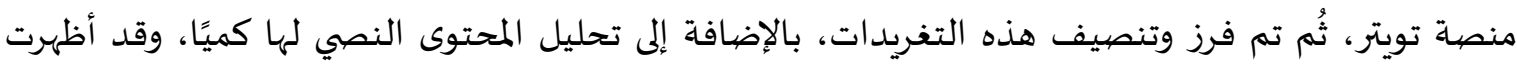

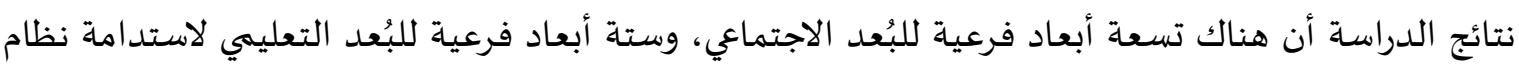
التعلم الإلكتروني في المملكة العربية السعودية. قامت أبو زاهره (2020) بدراسة هدفت إلى معرفة أثر استخدام التعليم المدمجج على التحصيل المعرفي وبقاء أثراء

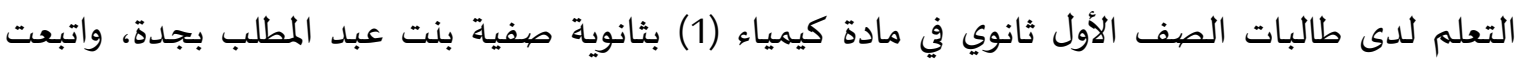
الدراسـة المنهج التجريبي من خلال اختيار شعبة كعينة تجريبية وشعبة كعينة ضابطة، وأظهرت نتائج الدراسة 
وجود فروق ذات دلالة احصائية بين متوسط درجات طالبات العينة التجريبية والعينة الضابطة في الاختبار

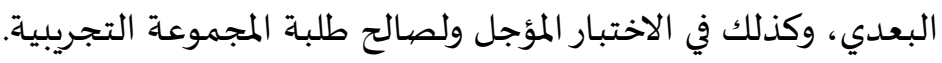

التعقيب على الدراسات السابقة:

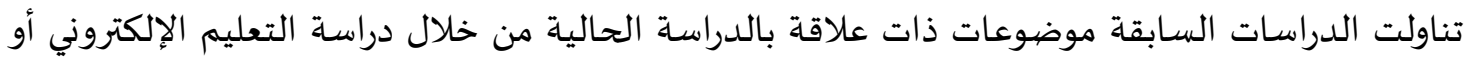

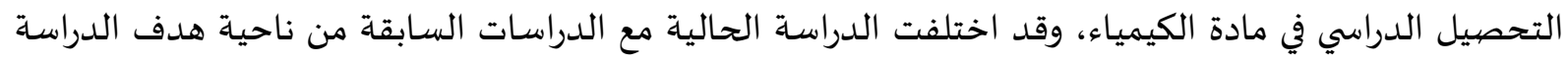

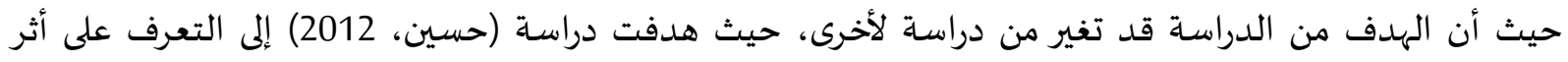

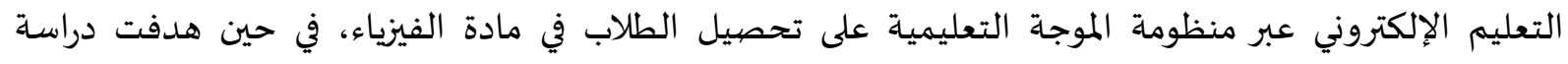

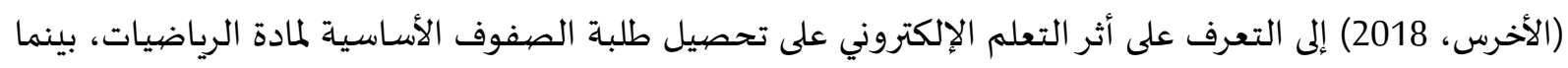

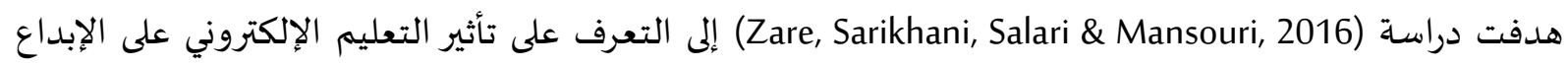

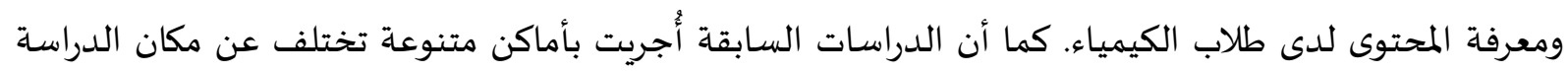
الحالية، حيث تناولت دراسة (Franklin \& Nahari, 2018) عينة مكونة من (163) عضو هيئة تدريس في جامعة الملك المكاء

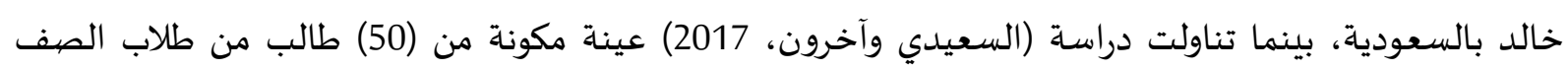

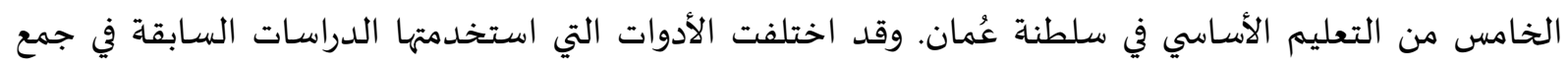

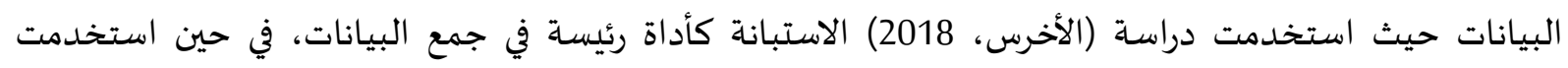

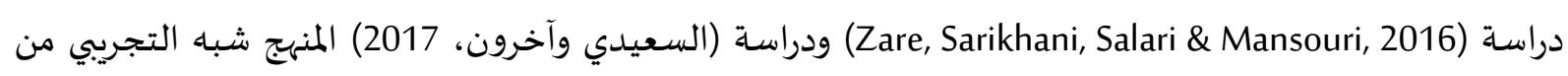
خلال تقسيم عينة الدراسة إلى مجموعتين تجريبية وضابطة. وقد استفادت الدراسة الحالية من هذه الدراسات بشكل كبير ساهم في تعريف مصطلحات الدراسـة، وتحديد مشكلتها وتطوير أداة جمع البيانات.

3- منهجية الدراسـة وإجراءاتها.

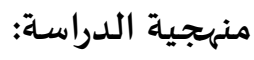
استخدمت الباحثة المنهج شبه التجريبي، ولاسيما أن المنهج شبه التجريبي يقوم بتحديد الظاهرة، وملاحظة التغييرات الناجمة عنها، ثم تحليل هذه التغيرات وتفسيرها، وهذا ما يتناسب مع الدراسة الحسالية المالية.

مجتمع الدراسة: تكون مجتمع الدراسة من جميع طالبات الصف الثاني ثانوي في مدينة جدة، والبالغ عددهن (3000) طالبة

للعام الدراسي (2021/2020).

عينة الدراسـة: تضمنت عينة الدراسة (100) طالبة من طالبات الصف الثاني ثانوي في مدرسة صفية بنت عبد المطلب

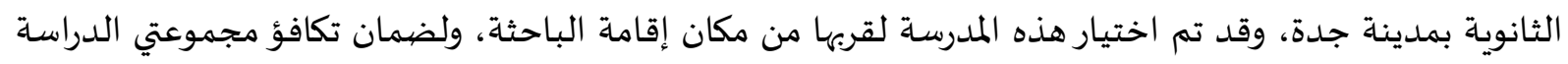

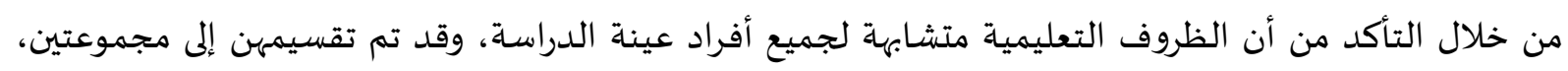

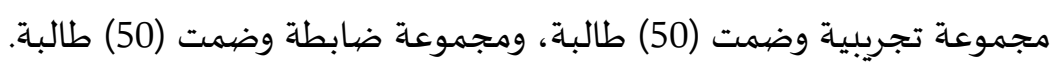




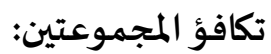

قبل البدء بالتجربة تم إجراء الاختبار القبلي للتأكد من تكافؤ طالبات المجموعتين التجريبية والضابطة،

$$
\text { والجدول (1)، يبين نتائج ذلك. }
$$

جدول (1) المتوسطات الحسابية والانحرافات المعيارية وقيمة (t) لمجموعتي الدراسة في الاختبار القبلي

\begin{tabular}{|c|c|c|c|c|c|c|}
\hline مستوى الدلالة & قيمة & الانحراف & المتوسط الحسابي & العدد & المتغير & $\hat{\imath}$ \\
\hline \multirow{2}{*}{.439} & \multirow{2}{*}{.345} & 4.84 & 35.42 & 50 & المجموعة الضيابطة & 1 \\
\hline & & 4.43 & 35.10 & 50 & المجموعة التجريبية & 2 \\
\hline
\end{tabular}

يظهر الجدول رقم (1) عدم وجود فروق ذات دلالة إحصائية عند مستوى الدلالة (10.05) بين المجموعة

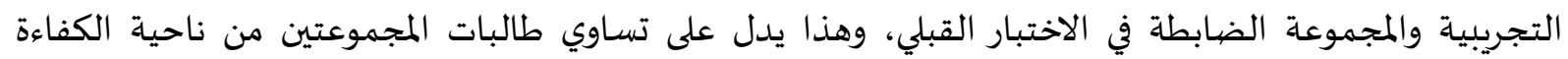

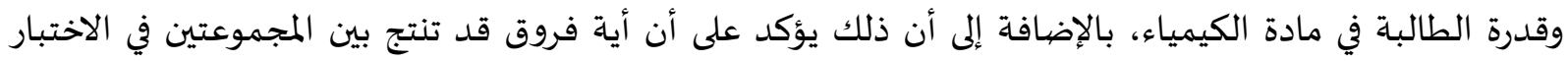
البعدي ستكون بسبب اختلاف طريقة التدريس، وليس هنالك أي مؤثر خارجي.

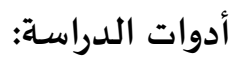

لتحقيق أهداف الدراسة قامت الباحثة باختيار الفصل الأول من منهاج الكيمياء للصف الثاني ثانوي والمعنون (بالإلكترونات في الذرات) ويتضمن هذا الفصل ثلاثة دروس هي الضوء وطاقة الكم، ونظرية الكم والذرة، والتوزيع الإلكتروني.

كما قامت الباحثة بإعداد اختبار تحصيلي لمادة الكيمياء للصف الثاني ثانوي، بعد تحليل المحتوى للمادة

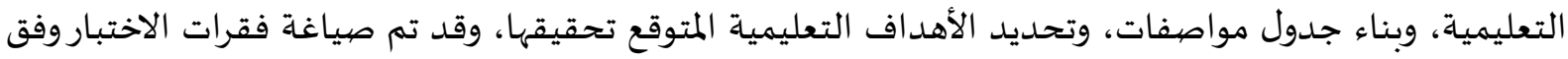

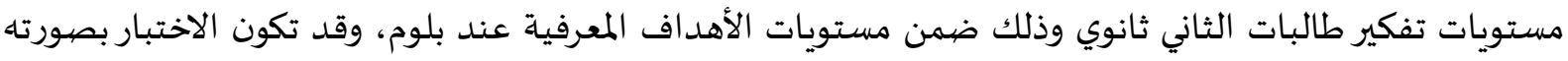
الأولية من (12) سؤال، كالآتي: مستوبات تفرير

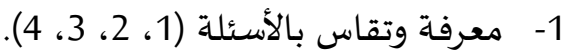

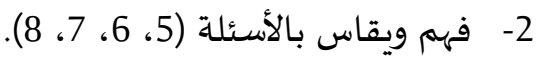

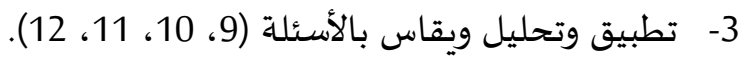

وقد حددت الباحثة العلامة القصوى ب(50)، وقد تم تحديد وقت الاختبار بساعة ونصف.

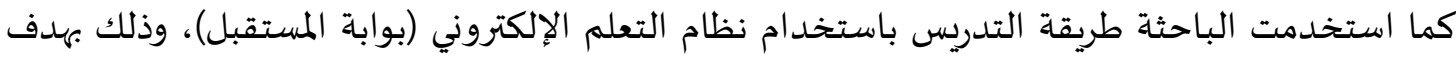
تدريس المحتوى العلمي للفصل الأول من مادة الكيمياء لطالبات المجموعة التجريبية.

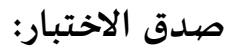

للتحقق من صدق الاختبار تم عرضيه على عدد من المحكمين المختصين في المناهج وأساليب تدردس

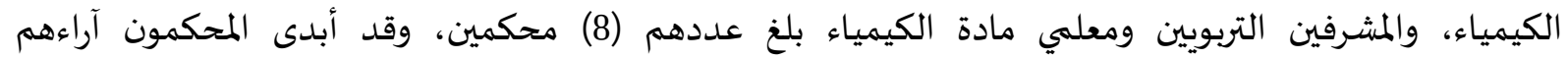

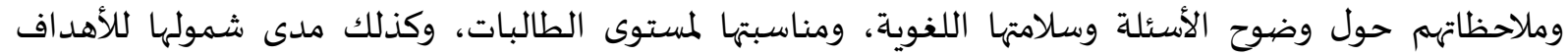

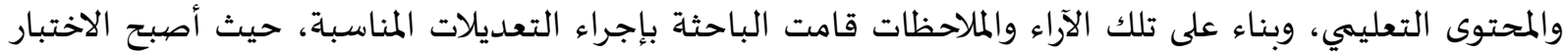
التحصيلي بصورته النهائية يتكون من (12) سؤال. 


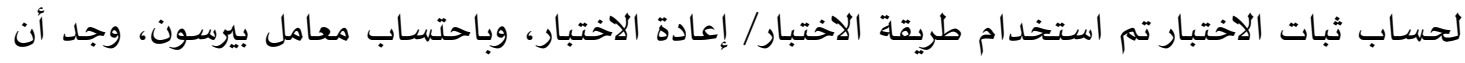

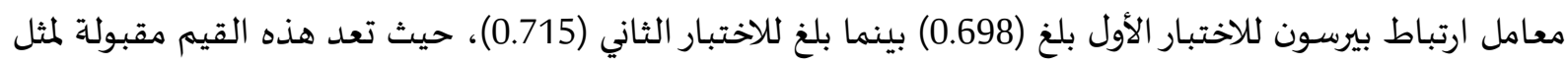
هذه الدراسة.

معاملات الصعوبة والسهولة والتمييز: تم احتساب معاملات الصعوبة والسهولة والتمييز للاختبار المُعد في هذه الدراسـة، والجدول التالي يوضح نتائج ذلك: جدول (2) معاملات السهولة والصعوبة والتمييز للاختبار التحصيلي

\begin{tabular}{|c|c|c|c|}
\hline معامل التمييز & معامل الصيعوبة & معامل السهولة & السؤال \\
\hline 0.24 & 0.06 & 0.94 & السؤال الأول \\
\hline 0.1 & 0.01 & 0.99 & السؤال الثاني \\
\hline 0.14 & 0.02 & 0.98 & السؤال الثالث \\
\hline 0.17 & 0.03 & 0.97 & السؤال الرابع \\
\hline 0.32 & 0.12 & 0.88 & السؤال الخامس \\
\hline 0.14 & 0.02 & 0.98 & السؤال السـادس \\
\hline 0.24 & 0.06 & 0.94 & السؤال السـابع \\
\hline 0.26 & 0.07 & 0.93 & السؤال الثامن \\
\hline 0.17 & 0.03 & 0.97 & السؤال التاسع \\
\hline 0.29 & 0.09 & 0.91 & السؤال العاشر \\
\hline 0.41 & 0.22 & 0.78 & السؤال الحادي عشر \\
\hline 0.41 & 0.21 & 0.79 & السؤال الثاني عشر \\
\hline
\end{tabular}

الأساليب الإحصيائية المستخدمة:

استخدمت الباحثة برنامج التحليل الإحصائي للعلوم الاجتماعية (SPSS. 25) وذلك لتحليل بيانات الدراسة واستخراج النتائج، حيث تم ذلك من خلال استخدام مجموعة من الأساليب الإحصائية كالمتوسطات الحسابية الحابية،

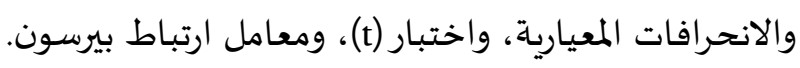

4- عرض النتائج ومناقشتها.

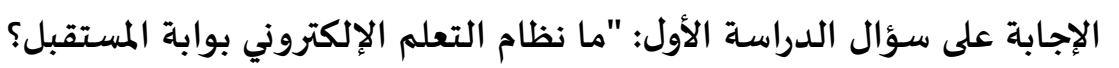

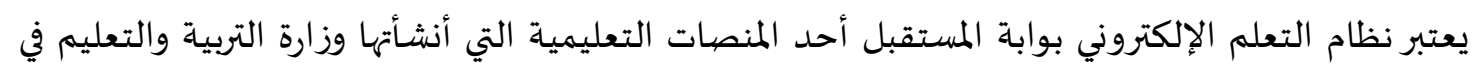
المملكة العربية السعودية، وذلك ضمن مساعيها لتطوير العملية التعليمية من خلال استخدام تقنيات تكنولوجيا

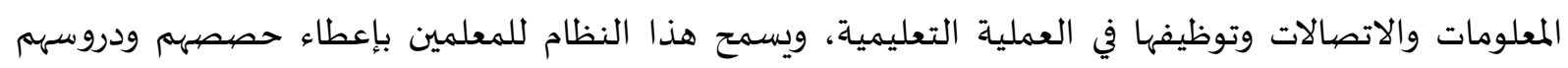

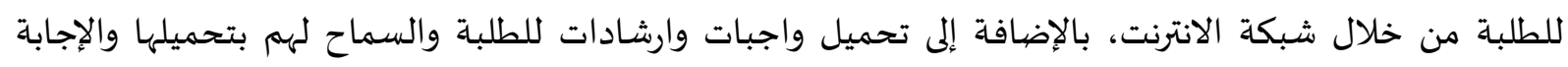
عليها من خلال نظام بوابة المستقبل. 
وقد سعت وزارة التربية والتعليم السعودية من خلال نظام بوابة المستقبل إلى إنشاء بذرة التحول الرقهي

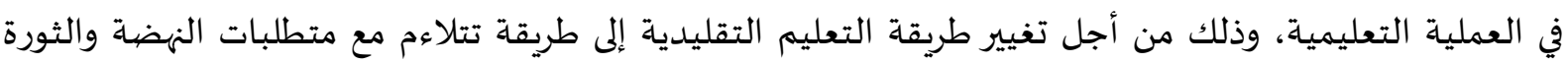

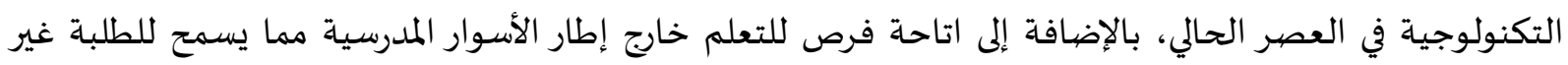
القادرين على الذهاب للمدرسة بالتعلم. كما يعتبر نظام بوابة المستقبل من الأنظمة الحديثة والمتطورة للتعليم الإلكتروني في المملكة العربية السعودية، حيث يتسم هذا النظام بقدرتِ على حماية الخصوصية والأمان لجميع المشتركين من خلال إعلى إعطاء

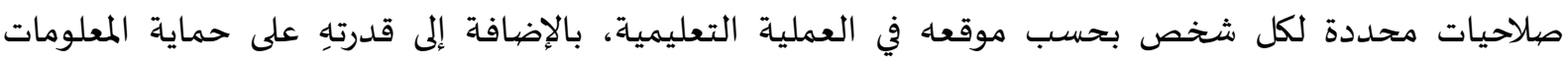
والملفات من الضياع أو التلف من خلال وجود نسخ احتخ احتياطية لها.

الإجابة على سؤال الدراسة الثاني: هل توجد فروق ذات دلالة إحصائية عند مستوى (X<0.05) في مستوى

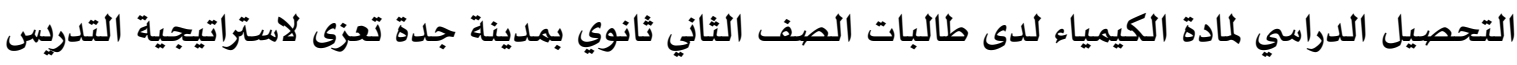

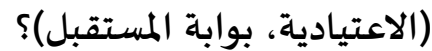

وللإجابة عن هذا السؤال؛ تمّ احتساب المتوسّطات الحسابية والانحرافات المعياريّة وقيمة (t)، لعلامات الاختبار البعدي في كلتا المجموعتين، والجدول (3) يوضيح نتائج ذلك:

جدول (3) المتوسطات الحسابية والانحرافات المعيارية وقيمة (t) لمجموعات الدراسة في الاختبار البعدي دئي

\begin{tabular}{|c|c|c|c|c|c|c|}
\hline مستوى الدلالة & $\begin{array}{l}\text { قيمة } \\
\text { (t) }\end{array}$ & الانحراف & المتوسطابي & العدد & المتخير & $\hat{\imath}$ \\
\hline \multirow{2}{*}{.002} & \multirow{2}{*}{4.986} & 4.24 & 36.82 & 50 & المجموعة الضيابطة (الطريقة التقليدية) & 1 \\
\hline & & 2.73 & 40.38 & 50 & المجموعة التجريبية (طريقة بوابة المستقبل) & 2 \\
\hline
\end{tabular}

يظهر الجدول رقم (3) أن هنالك فروق ذات دلالة إحصائية عند مستوى الدلالة (10.05) بين المجموعة

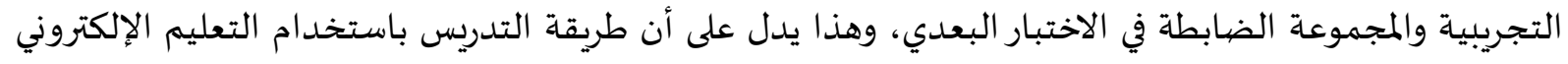

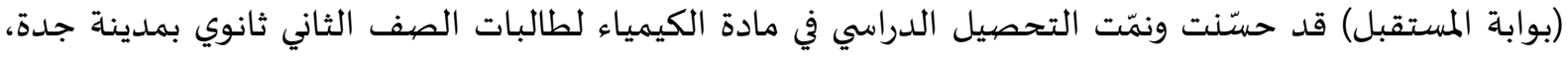

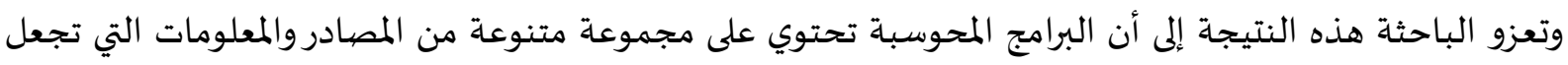

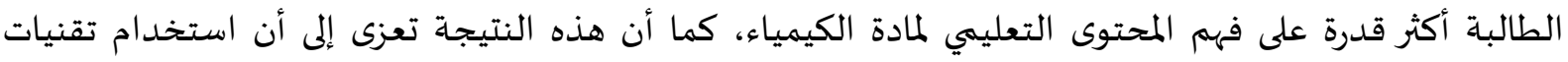

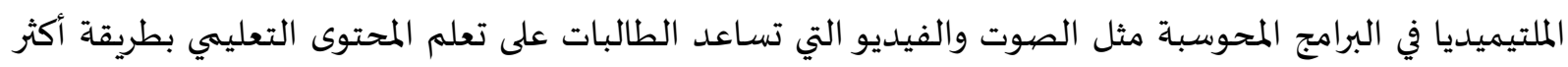

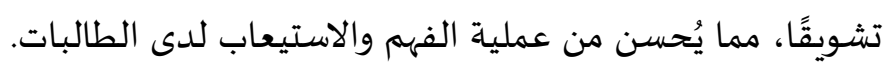
كما تعزو الباحثة هذه النتيجة إلى الأثر البالغ الأهمية لنظام التعلم الإلكتروني (بوابة المستقبل) على الماتل

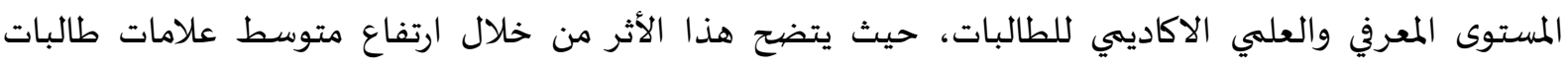

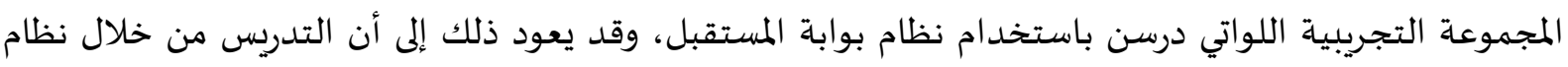

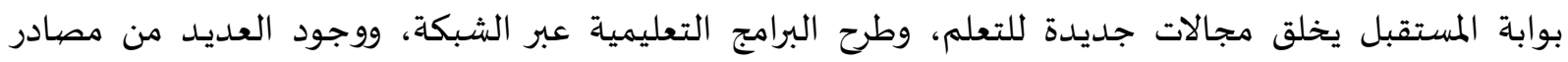

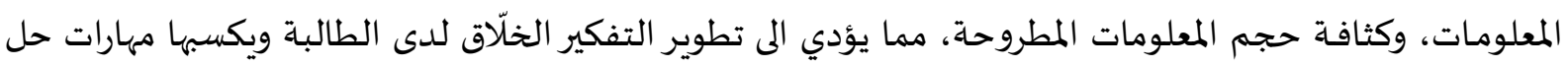
المشكلات ويُحسن من مستوى فهمها للمادة العلمياة.

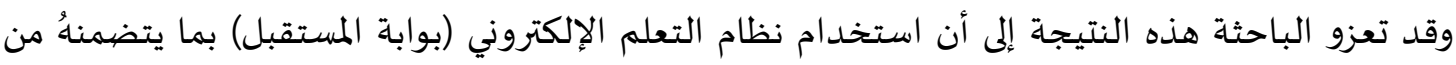

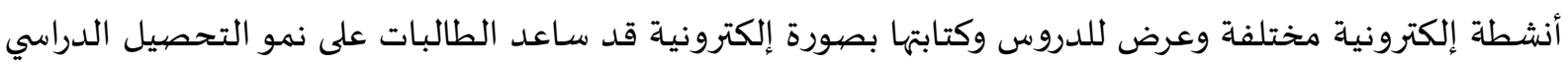


وذلك من خلال الأنشطة التفاعلية والمواقع الإلكترونية والتغذية الراجعة الفورية والحوار وغرف الدردشة والمنتديات وحل الواجبات والاختبارات الإلكترونية.

وتتفق هذه النتيجة مع دراسة (حسين، 2012) التي توصلت إلى تفوق استراتيجية التعليم الإلكتروني على الجى

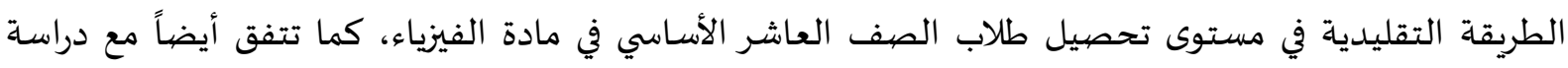
(السعيدي وآخرون، 2017) والتي توصلت إلى وجود أثر للتعليم الإلكتروني في تدريس الرياضيات على التحصيل الدراسي، كما تتفق هذه النتيجة مع نتيجة دراسة (Zare et al., 2016) التي توصلت إلى أن التعلم الإلكتروني فعّال

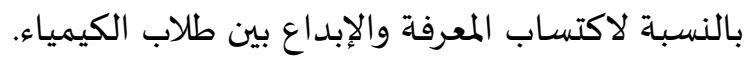
التوصيات والمقترحات. الاعتماد على ما توصلت إليه الدراسة من نتائج، توصي الباحثة وتقترح ما يلي:

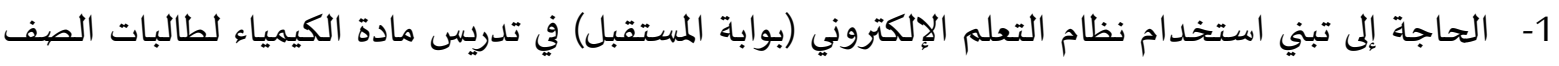

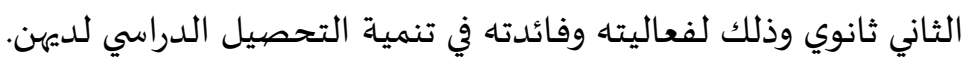
2- الاستمرار بتحديث وتطوير البنية التحتية التكنولوجية نظرًا لحاجة التعليم الإلكتروني لأدوات وبرمجيات تكنولوجية متطورة تتلاءم مع متطلبات المرحلة الحالية، وذلك من خلال تحديث وتطوير برمجيات التهبية التعليم الإلكتروني بشكل مستمر، وتطوير المعدات المستخدمة في التعليم الإلكتروني كشبكة الإنترنت وأجهزة

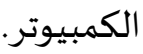

3- الحاجة إلى عقد ورش عمل لتدريب معلمي المدارس على كيفية استخدام نظام التعلم الإلكتروني (بوابة المستقبل) في تصميم دروس تعليمية للطلبة. 4- ضرورة تحسين أساليب عرض المحتوى الإلكتروني للمناهج لتعزيز مستوى استيعاب الطالبة وفهمهيم، وبما

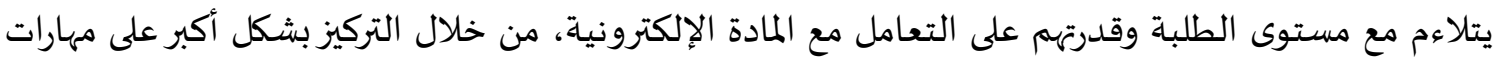
التفكير الإبداعي ومهارات حل المشكلات لدى لدى الطلبة. 5- الحاجة لمزيد من الدراسات عن الفوائد التعليمية الفعلية لاستخدام نظام التعلم الإلكتروني (بوابة المستقبل)

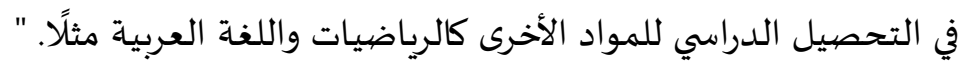
- أبو زاهره، ناديه (2020). أثر استخدام التعليم المدمج على التحصيل المعرفي في مادة الكيمياء (1) وبقاء أثر المراء

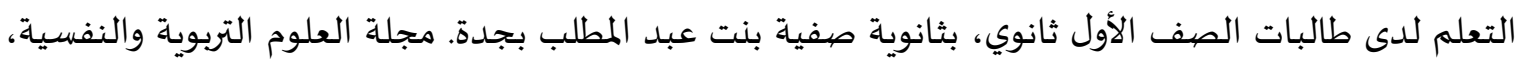
.168-154، (16)4 أبو سوار، قمر السيد حسن (2013). فعالية استخدام الكتاب الإلكتروني في التحصيل الدراسي لمادة الحاسوب للمرحلة الثانوية. رسالة ماجستير، جامعة الزعيم الأزهري، السودان. السوان. الأخرس، يوسف (2018). أثر تطبيق استراتيجية التعليم الإلكتروني على التحصيل الدارسي في في مادة الرياضيات في في الريات الصفوف الأساسية في محافظة العاصمة من وجهة نظر معلمي ومعلمات الرياضيات. دراسات العلوم التربوية، 80-70، 45 
باروم، سميرة (2005). اتجاهات طلاب جامعة الملك عبد العزيز نحو التعليم عن بعد. مجلة الآداب والعلوم الإنسانية، 15(15)، 39-15.

بيان، منال (2004). أثر برنامج حاسوبي للتربية المرورية مصمم وفق مدخل النظم لإعداد المعلمين في التحصيل

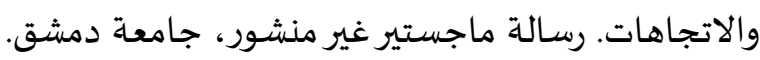
الجار الله، سليمان؛ والخريجي، عبد الله (2020). استدامة نظام التعلم الإلكتروني في المملكة العربية السعودية داتية

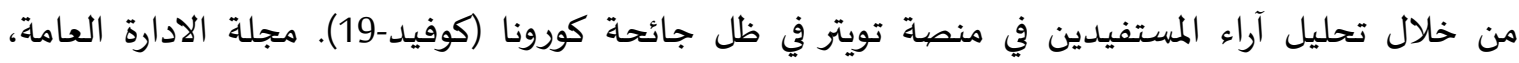
60 (عدد خاص)، حدة، لانا (2013). علاقة التحصيل الدراسي بدافعية التعلم لدى المراهق المتمرس، دراسة ميدانية لتلاميذ السنة الرابعة متوسط. رسالة ماجستير غير منشورة، جامعة أكلي محند أو الحاج، الجزائر.

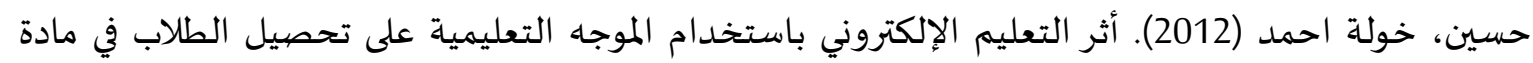

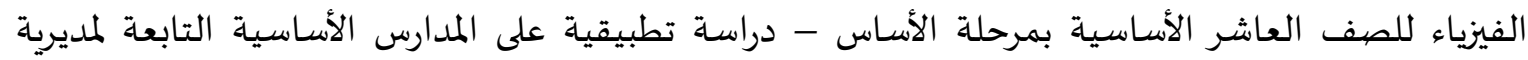
التربية والتعليم في محافظة جرس (2010-2012). رسالة ماجستير، جامعة الزعيم الأزهري، السودان.

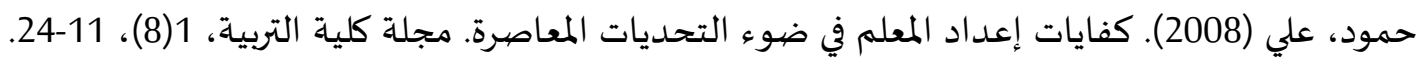
الحيحي، آية (2018). أثر استخدام استراتيجية الذكاء المنطقي - الرياضي في تدريس مادة الكيمياء في التحصيل

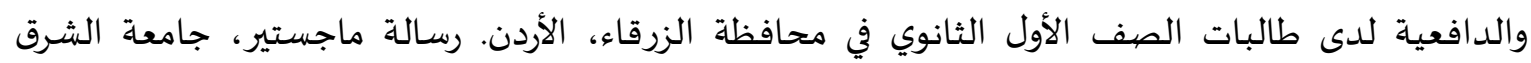
الأوسط الأردن. الربيعي، محمود داود سلمان (2006). طرائق وأساليب التدريس المعاصرة. الاردن: عالم الكتب، جدارا للكتاب العالي. الزغول، عماد الدين عبد الرحيم؛ المحاميد، شاكر عقلة (2007). سيكولوجية التدريس الصفي. عمان: دار المسيرة للنشر والتوزيع. السعيدي، محمد؛ الكحالي، خلفان؛ البريكي، محمد؛ البلوشي، عبد الرحمن؛ والخروصي، حسين (2017). أثر الثرإ

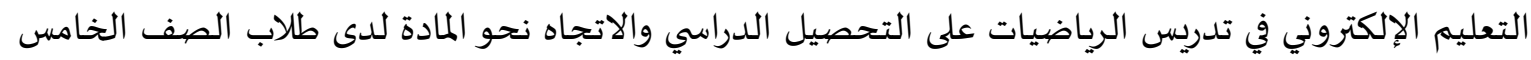

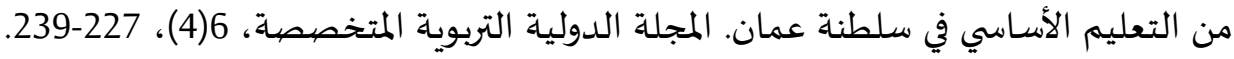
سمارة، نواف؛ والعديلي، طه (2018). فاعلية التدريس بالمختبر الجاف في اكتساب المفاهيم الكيميائية لدى

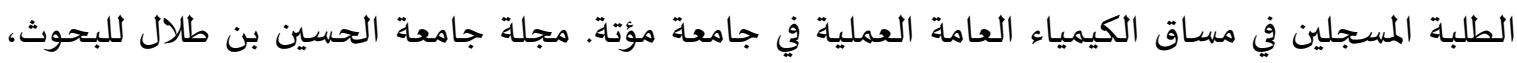
$.131-112 ،(2) 4$ الشناق، قسيم وبني دومي، حسن (2010). اتجاهات المُدرسين والطلبة نحو استخدام التعلم الإلكتروني في

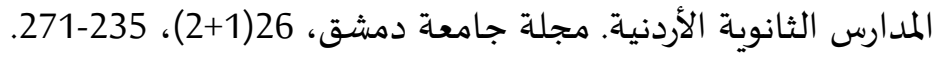
عابد، رسمي علي (2008). ضعف التحصيل الدراسي، أسبابه وعلاجه. عمان: دار جرير للنشروالتوزيع. عبد الحميد، عبد العزيز (2010). التعليم الإلكتروني ومستحدثات تكنولوجيا التعليم. مصر: المكتبة العصرية للنشر والتوزيع. عبد العاطي، حسن الباتع؛ وأبو خطوة، السيد عبد المولى (2012). التعليم الإلكتروني الرقمي (النظرية -

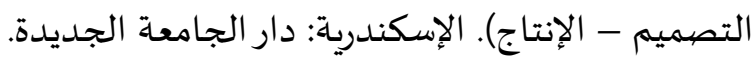


عبد المنعم، محمد (2003). مستحدثات التكنولوجيا في مجال التعليم وطبيعتها وخصائصها. سلسلة دراسات

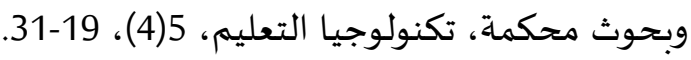
- عثمان، أنور احمد (2009). الفصول الإلكترونية ودورها في تحقيق مفهوم التعليم عن بعد. أطروحة دكتوراه في

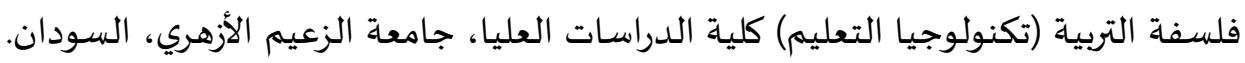

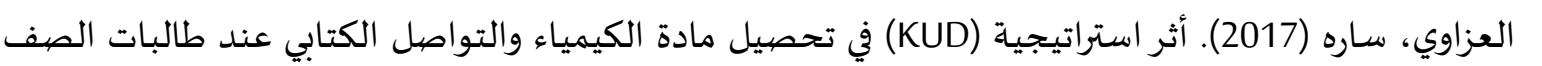

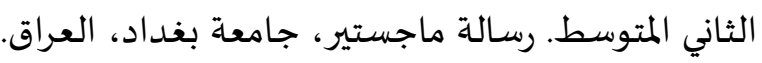
عسيري، أحمد (2016). فاعلية وحدة تعليمية إلكترونية في الجغرافيا على التحصيل الدراسي وبقاء أثر التعلم

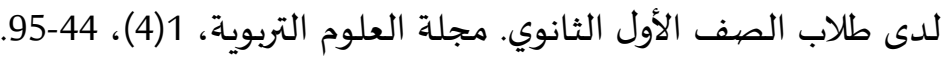
عميرة، جويدة؛ وطرشون، عثمان؛ وعليان، علي (2019). خصائص وأهداف التعليم عن بُعد والتعليم

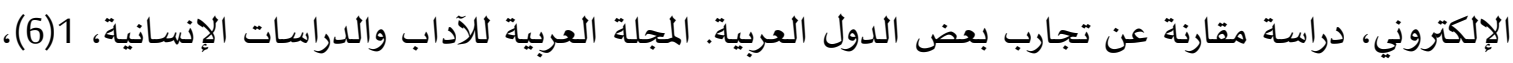
.298-285

قشمر، علي (2019). أثر التدريس باستخدام التعلم بالاكتشاف على تحصيل طلبة المدارس الحكومية

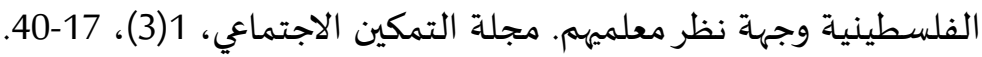
قطامي، يوسف؛ وقطامي، نايفة (2001). سيكولوجية التدريس. ط1، عمان: داريه دار الشروق. محسون، إبراهيم محمود (2003). فعالية وحدة في الفيزياء باستخدام الوسائط المتعددة في تحصيل طلاب الصف الأول الثانوي. رسالة ماجستير غير منشورة، جامعة القاهرة، مصردر. مصطفى، فهيم (2001). مشكلات القراءة من الطفولة إلى المراهقة التشخيص والعلاج. القاهرة: دار الفكر العربي.

الموسى، عبد الله (2002). التعليم الإلكتروني. السعودية: مكتبة التربية جامعة الملك سعود.

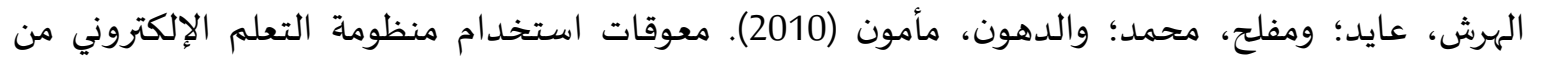

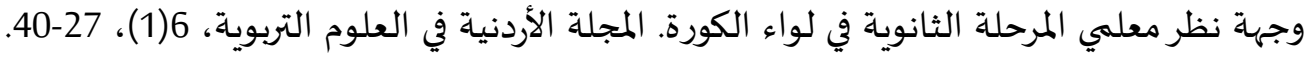
- اليوسفي، زينب (2015). فاعلية استخدام تكنولوجيا الواقع المدمج وأثرها في تدريس الأبجدية الإنجليزية لأطفال الرياض في الدولة الكويت. رسالة ماجستير غير منشورة، جامعة الكويت، الكويت.

\section{ثانياً- المراجع بالإنجليزية:}

- Algahtani, H., Shirah, B., Subahi, A., Aldarmahi, A., Ahmed, S. N., \& Khan, M. A. (2020). Perception of Students about E-learning: A Single-center Experience from Saudi Arabia. Medical Journal: http://dx.doi.org/10.2991/dsahmj.k.200327.001.

- Boettcher, J. V \& Conrad, R.M. (2010). The online teaching survival guide: Simple and practical pedagogical tips. John Wiley \& Sons.

- Franklin, U \& Nahari, A. (2018). The Impact of E-Learning on Academic Performance: Preliminary Examination of King Khalid University. International Journal of Academic Research in Progressive Education and Development, 7(1), 2226-6348. 
- Tegene, K. (2014). The Influence of E-Learning on the Academic Performance of Mathematics Students in Fundamental Concepts of Algebra Course: The Case in Jimma University. Ethiop. J. Educ. \& Sc, 9(2), 41-59.

- Zare, M., Sarikhani, R., Salari, M \& Mansouri, V. (2016). The impact of E-learning on university students' academic achievement and creativity. Journal of Technical Education and Training, 3(2), 2533. 